Pedro Ming Azevedo

\title{
O polimorfismo do antagonista do receptor da interleucina-1 (IL1RN) como fator contribuinte para gravidade da cardite reumática em brasileiros
}

Tese apresentada à Faculdade de Medicina da Universidade de São Paulo para obtenção do título de Doutor em Ciências

Área de concentração: Processos imunes e Infecciosos Orientadora: Profa. Dra. Rosa Maria Rodrigues Pereira

São Paulo 2009 
Dados Internacionais de Catalogação na Publicação (CIP)

Preparada pela Biblioteca da

Faculdade de Medicina da Universidade de São Paulo

Creprodução autorizada pelo autor

\section{Azevedo, Pedro Ming}

O polimorfismo do antagonista do receptor da interleucina-1 (IL1RN) como fator contribuinte para gravidade da cardite reumática em brasileiros / Pedro Ming Azevedo. -- São Paulo, 2009.

Tese(doutorado)--Faculdade de Medicina da Universidade de São Paulo.

Departamento de Clínica Médica.

Área de concentração: Processos Imunes e Infecciosos.

Orientadora: Rosa Maria Rodrigues Pereira.

Descritores: 1.Receptores de interleucina-1 2.Polimorfismo genético 3.Febre reumática 4.Cardiopatia reumática

USP/FM/SBD-226/09 
Dedico este trabalho às crianças e adolescentes com febre reumática e suas famílias 
À minha esposa Caroline e ao meu filho Caio, sem os quais nada disso, ou qualquer outra coisa, teria a menor importância.

Aos meus pais, que sempre deram seu melhor a nós e ao mundo. 


\section{Agradecimentos}

À orientadora, Profa. Dra. Rosa Maria Rodrigues Pereira, que com (relativa) calma e muita competência muito me ensinou e ajudou a lidar com cada pedra no caminho.

À Professora Luiza Guilherme, profundamente, por sua ajuda e suporte na elaboração da discussão de nosso artigo.

À Valeria de Falco Caparbo, extensão de meus braços, por toda ajuda e conhecimentos biotécnicos emprestados.

À Raquel Bauer, pela valiosa ajuda na coleta de dados e no trabalho laboratorial.

Ao Professor Clovis Artur Almeida Silva, por ter cedido o ambulatório de Febre Reumática do Instituto da Criança, um relógio que funciona com precisão movida a seus esforços e competência.

À Disciplina de Reumatologia, através da Profa. Dra. Eloisa Bonfá, pelo ambiente propício ao trabalho e pesquisa. 
Este trabalho foi financiado pelo Conselho Nacional de Desenvolvimento Científico e Tecnológico, CNPQ \# 305691/2006 (para RMRP). 


\section{Normalização adotada}

Esta tese está de acordo com as seguintes normas, em vigor no momento da publicação:

Referências: adaptado de International Committee of Medical Journals Editors (Vancouver)

Universidade de São Paulo. Faculdade de Medicina. Serviço de Biblioteca e Documentação. Guia de apresentação de dissertações, teses e monografias. Elaborado por Anneliese Carneiro da Cunha, Maria Júlia de A. L. Freddi, Maria F. Crestana, Marinalva de Souza Aragão, Suely Campos Cardoso, Valéria Vilhena. $2^{a}$ ed. São Paulo: Serviço de Biblioteca e Documentação; 2005.

Abreviaturas dos títulos dos periódicos de acordo com List of Journals Indexed in Index Medicus. 


\section{Sumário}

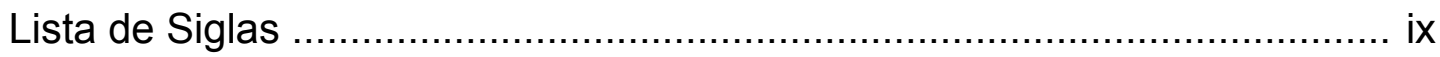

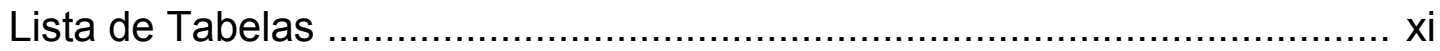

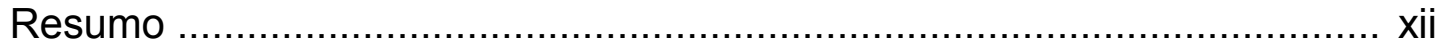

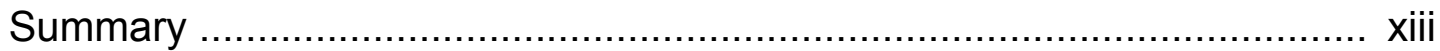

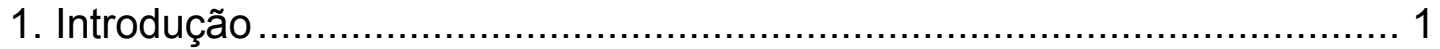

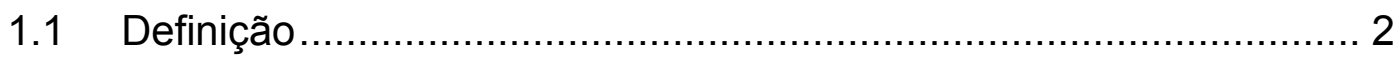

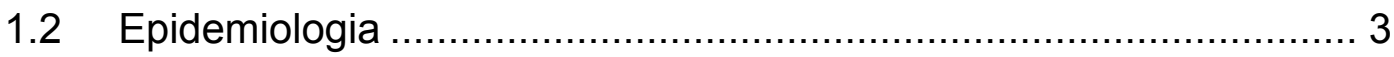

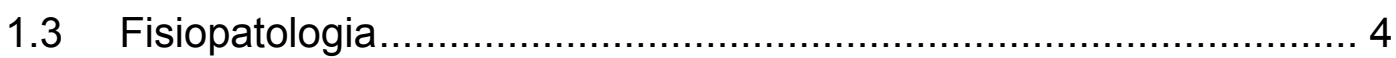

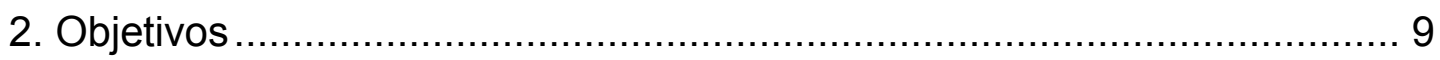

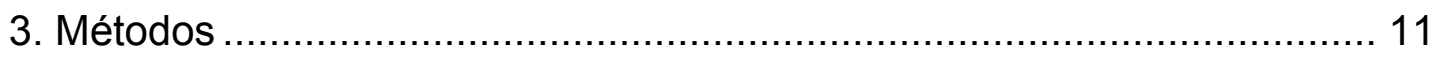

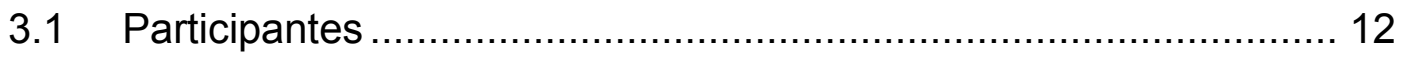

3.2 Determinação Genotípica do IL1RN ……….............................. 14

3.3 Análise Estatística .................................................................... 15

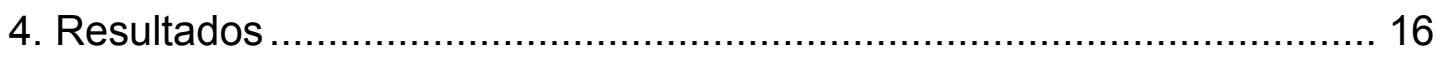

4.1 Características dos Participantes ………….............................. 17

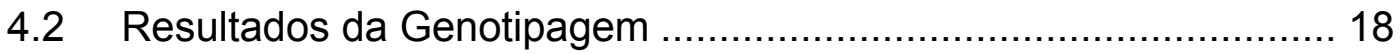

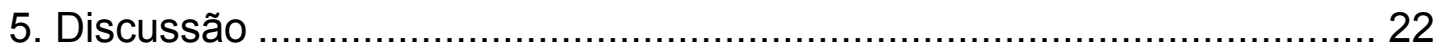

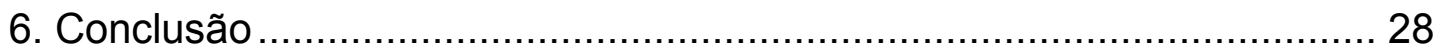

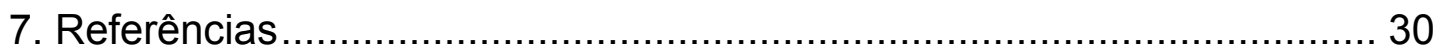

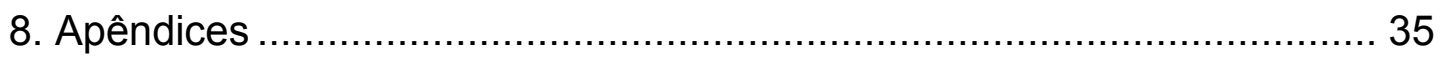

8.1 Artigo para publicação …………......................................... 36

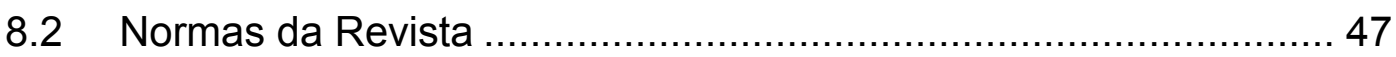




\section{Lista de Siglas}

A1 Alelo 1 para o gene codificador do antagonista do receptor da interleucina-1

A2 Alelo 2 para o gene codificador do antagonista do receptor da interleucina-1

A1/A1 Genótipo homozigoto para o alelo 1 do gene codificador do antagonista do receptor da interleucina-1

A2/A2 Genótipo homozigoto para o alelo 2 do gene codificador do antagonista do receptor da interleucina-1

FRA Febre reumática aguda

CRA Cardite reumática aguda

ICC Insuficiência cardíaca congestiva

IC Intervalo de confiança

CRC Cardite reumática crônica

DNA DesoxiriboNucleic Acid (ácido desoxiribonucleico)

HLA Human Leukocyte Antigen (antígeno leucocitário humano)

IL Interleukin (interleucina)

IL1-RA Interleukin-1 Receptor Antagonist (antagonista do receptor da interleucina-1)

IL1RN Gene codifing the Interleukin-1 Receptor Antagonist (gene codificador do antagonista do receptor da interleucina-1) 
IL-2r Interleukin-2 Receptor (receptor da interleucina-2)

IFN-y Gama Interferon (interferon gama)

MHC Major Histocompatibility Complex (complexo de histocompatibilidade principal)

MVL Multi Valvar Lesion (lesão multi-valvar)

OR Odds Ratio (razão de probabilidade)

PBMC Peripheral Blood Mononuclear Cells (células mononucleares derivadas de sangue periférico)

FR $\quad$ Febre reumática

CG Cardite Grave

FE Faringite streptococica

Th1 T helper lynphocyte Type 1 (linfócitos T auxiliadores tipo 1)

Th2 T helper lynphocyte Type 2 (linfócitos T auxiliadores tipo 2)

TNF-a Tumor Necrosis Factor alpha (fator de necrose tumoral alfa) 


\section{Lista de Tabelas}

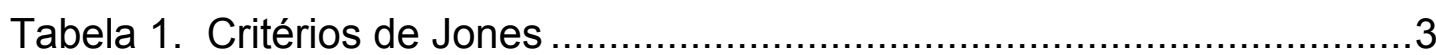

Tabela 2. Alelos do IL1RN segundo o número de repetições em tandem de $86 \mathrm{pb}$ no íntron 2 e sua prevalência aproximada na população

Tabela 3. Características Clínicas dos pacientes com Febre Reumática ....18

Tabela 4. Taxa de porte para os alelos do IL1RN e freqüência genotípica em pacientes com Febre Reumática e controles normais

Tabela 5. Taxa de porte dos alelos e freqüência genotípica para o ILIRN em relação ao envolvimento cardíaco (Cardite e Cardite Grave) em pacientes com Febre Reumática .20

Tabela 6. Taxa de porte e freqüência genotípica para o IL1RN em relação às manifestações não cardíacas nos pacientes com Febre Reumática 


\section{Resumo}

Azevedo PM. O polimorfismo do antagonista do receptor da interleucina-1 (IL1RN) como fator contribuinte para gravidade da cardite reumática em brasileiros [tese]. São Paulo: Faculdade de Medicina, Universidade de São Paulo; 2009. 34p.

A febre reumática (FR) é uma doença imuno-mediada, na qual citoquinas pró-inflamatórias têm um importante papel. Uma produção exacerbada de interleucina-1 (IL-1) parece ser um evento precoce entre as anormalidades imunológicas observadas na FR. $\mathrm{O}$ antagonista do receptor de IL-1 (IL1-RA) é um inibidor competitivo endógeno do receptor da IL-1. A razão IL-1RA/IL-1 é importante na determinação da intensidade e duração da resposta inflamatória. O alelo 2 (A2) do gene codificador do IL1-RA (IL1RN) tem sido relacionado a um número de doenças inflamatórias e autoimunes, bem como a uma maior resistência a infecções. Considerando que a FR é uma doença inflamatória autoimune desencadeada por uma infecção bacteriana, nós avaliamos o polimorfismo do IL1RN com o intuito de determinar possível relevância na susceptibilidade à $F R$ e suas manifestações clínicas. O genótipo de 84 pacientes com FR e 84 controles pareados por raça foram determinados através da análise do número de repetições em tandem de $86 \mathrm{pb}$ no segundo íntron do IL1RN. O DNA foi extraído de leucócitos de sangue periférico e amplificado com sondas específicas. Dados sobre as manifestações clínicas da FR foram obtidos através de questionários padronizados e extensa revisão de prontuários. Cardite foi definida como sopro cardíaco novo auscultado por médico treinado com a correspondente regurgitação ou estenose valvar ao ecocardiograma. Cardite foi definida como grave na presença de insuficiência cardíaca congestiva ou da indicação de cirurgia cardíaca. A associação estatística entre genótipos, FR e suas variações clínicas foram determinadas. A presença do alelo 1 (A1) e do genótipo A1/A1 foram menos freqüentemente encontradas entre pacientes com cardite severa quando comparado a pacientes sem esta manifestação $(\mathrm{OR}=0.11, \mathrm{p}=0.031$; $\mathrm{OR}=$ 0.092, $p=0.017)$. Nenhum dos dois alelos, A1 e A2, foram associados à presença de FR $(p=0.188 ; p=0.106)$, cardite sensu latu, $(p=0.578$ e $p=0.767)$, poliartrite $(p=0.343$ e $p=0.313)$ ou coréia $(p=0.654$ e $p=0.633)$.

Em conclusão, na população brasileira estudada o polimorfismo do IL1RN parece ser um fator relevante para a gravidade da cardite reumática.

Descritores: 1.IL1RN 2.Polimorfismo Genético 3.Febre Reumática 4.Doença reumática cardíaca. 


\section{Summary}

Azevedo PM. Interleukin-1 receptor antagonist gene (IL1RN) polymorphism as a contributing factor for the severity of Rheumatic Carditis in a Brazilian cohort [Thesis]. São Paulo: "Faculdade de Medicina, Universidade de São Paulo"; 2009. 34p.

Rheumatic fever (RF) is an immune-mediated disease in which proinflammatory cytokines play an important role. Exacerbated Interleukin-1 (IL1) production seems to be an early event in the immunological abnormalities that are observed in RF. The Interleukin-1 receptor antagonist (IL-1ra) is an endogenous competitive inhibitor of IL-1. The IL-1ra/IL-1 ratio is important in evaluating the intensity and duration of the inflammatory response. The second allele (A2) for the IL-1ra gene (IL1RN) has been related to a number of inflammatory and autoimmune diseases as well as to a greater resistance to infections. Considering that RF is an inflammatory autoimmune disease that is triggered by a bacterial infection, we have evaluated the IL1RN polymorphism and its possible relevance to the susceptibility to RF and its clinical manifestations. The genotypes of 84 RF patients (Jones criteria) and 84 normal race-matched controls were determined through the analysis of the number of 86-bp tandem repeats in the second intron of IL1RN. The DNA was extracted from peripheral-blood leukocytes and amplified with specific primers. Clinical manifestations of RF were obtained through a standardized questionnaire and an extensive chart review. Carditis was defined as new onset cardiac murmur that was perceived by a trained physician with corresponding valvae regurgitation or stenosis on echocardiogram. Carditis was classified as severe in the presence of congestive heart failure or upon the indication for cardiac surgery. The statistical association among the genotypes, RF and its clinical variations was determined. The presence of allele 1 and the genotype A1/A1 were found less frequently among patients with severe carditis when compared to patients without this manifestation $(O R=0.11, p=0.031 ; O R=0.092, p=0.017)$. Neither allele 1 nor allele 2 were associated with the presence of RF $(p=0.188 ; p=0.106)$, overall carditis $(p=0.578$ and $p=0.767)$, polyarthritis $(p=0.343$ and $p=0.313)$ and chorea $(p=0.654$ and $p=0.633)$. In conclusion, for this Brazilian cohort, the polymorphism of the IL-1ra gene is a relevant factor for rheumatic heart disease severity.

Descriptors: 1.IL1RN 2.Gene Polymorphism 3.Rheumatic Fever 4.Rheumatic Heart Disease. 
1. INTRODUÇÃO 


\subsection{DEFINIÇÃO}

Febre Reumática é uma complicação tardia não supurativa de uma infecção faríngea por cepas de Streptococcus do grupo A de Lancefield. O quadro clínico característico consiste em um quadro febril agudo acompanhado de artrite migratória predominantemente de grandes articulações e/ou sinais clínicos ou laboratoriais de cardite e valvulite duas a três semanas após a faringite desencadeante (Ayoub, 2001). Sintomas secundários ao acometimento de sistema nervoso central (Coréia de Sydenham, alterações de comportamento) são menos freqüentes, mas muito sugestivos, e irão ocorrer após um período de latência mais longo, geralmente de 3 a 6 meses após a infecção (Ayoub, 2001). Os episódios agudos são auto limitados, mas as lesões valvares podem ser crônicas e progressivas, levando a disfunção cardíaca. O diagnóstico tem sido baseado nos critérios de Jones (Tabela 1). 
Tabela 1. Critérios de Jones (1992)

Critérios Modificados de Jones para o diagnóstico de Febre Reumática

\begin{tabular}{|c|c|}
\hline Manifestações Menores & Manifestações Menores \\
\hline Cardite & Achados Clínicos \\
\hline Poliartrite & Artralgia \\
\hline Coréia & Febre \\
\hline \multicolumn{2}{|l|}{ Eritema Marginatum } \\
\hline \multirow[t]{5}{*}{ Nódulos Subcutâneos } & Achados Laboratoriais \\
\hline & $\begin{array}{l}\text { Elevação de Reagentes de } \\
\text { Fase Ativa }\end{array}$ \\
\hline & $\begin{array}{l}\text { Elevação na Velocidade de } \\
\text { Hemossedimentação }\end{array}$ \\
\hline & $\begin{array}{l}\text { Elevação na Proteína } \\
\text { Reativa }\end{array}$ \\
\hline & $\begin{array}{l}\text { Prolongamento do intervalo } \\
\text { PR no ECG }\end{array}$ \\
\hline \multicolumn{2}{|c|}{ Evidências de Infecção previa pelo Streptococcus do Grupo A } \\
\hline \multicolumn{2}{|c|}{ Cultura faríngea ou teste rápido pra antígenos streptococicos positivos } \\
\hline \multicolumn{2}{|c|}{ Títulos elevados do Título de anticorpos anti-Streptococcus } \\
\hline
\end{tabular}

\subsection{EPIDEMIOLOGIA}

A incidência, gravidade e mortalidade da Febre Reumática declinaram dramaticamente nos países desenvolvidos durante o século 20. Notavelmente isto ocorreu antes da introdução de antibióticos na prática clinica. Em 1862, a Dinamarca apresentava cerca de 250 novos casos por 100.000 habitantes. Este número caiu para cerca de 100 por 100.000 habitantes em 1962. A partir de 1950, os antibiótico aceleraram este declínio até a marca de 0,23 a 1,88 novos casos por 100.000 habitantes, verificada em 1980. Três notáveis exceções a este declínio são as populações Neozelandeza, Havaiana e Maiori, de ancestralidade predominante polinésia, onde a incidência permanece cerca de 13,4 por 100.000 habitantes (Ayoub, 2001). 
Nos países em desenvolvimento a febre reumática (FR) continua sendo um grande fardo econômico e social.

No mundo, estima-se que ainda hoje ocorram a cada ano perto de 500.000 novos casos de febre reumática, determinando uma prevalência de mais de 15 milhões de casos de cardite reumática. Cerca de 233.000 pessoas morrem todos os anos em conseqüência desta moléstia. (Carapetis et al., 2005). Na América Latina, 21.000 casos de febre reumática aguda ocorrem anualmente. Os dados no Brasil são escassos. Em 2002, 5.000 casos novos foram reportados (IBGE).

\subsection{FISIOPATOLOGIA}

A patogênese da FR é complexa, e nela tanto fatores genéticos como ambientais parecem atuar (Ayoub, 2001). Estima-se que cerca de 0,3\% a 3,0\% dos indivíduos infectados por cepas de Streptococcus sabidamente reumatogênicas vão efetivamente desenvolver FR (Ayoub, 2001; Zabriskie, 1985), e aproximadamente um a dois terços deles desenvolverão cardite reumática (Gray et al., 1952; Guilherme et al., 2007; Wilson \& Schweitzer, 1954). A susceptibilidade à FR não é completamente compreendida, mas padrões de agregação familiar (Morris et al., 1993; Spagnuolo \& Taranta, 1968) e a maior concordância entre gêmeos idênticos em relação a gêmeos não idênticos sugerem influência genética (Hirsch et al., 1996). Da mesma forma, as semelhanças no padrão de apresentação clínica entre irmãos sugerem que as diferentes manifestações da doença podem apontar sua proximidade genética (Hirsch et al., 1996). 
Por outro lado, é bem conhecido que a FR é uma doença mediada pelo sistema imune, na qual citoquinas pró-inflamatórias têm importante papel. Uma produção exacerbada de interleucina-1 (IL-1) parece ser um evento precoce entre as anormalidades imunológicas observadas na FR, e é seguida pela produção de interleucina-2 (IL-2) (Spagnuolo \& Taranta, 1968). A produção de IL-1 e Interleucina-2 (IL-2) por células mononucleares está exacerbada em pacientes com FR aguda quando comparada a pacientes com faringite streptococica ou FR crônica latente (Spagnuolo \& Taranta, 1968).

O antagonista do receptor de IL-1 (IL1-RA) é um inibidor competitivo endógeno do receptor da IL-1. Ele se liga a este receptor sem induzir a cascata intracelular que sinaliza as ações pró-inflamatórias da IL-1 (Figura 1).

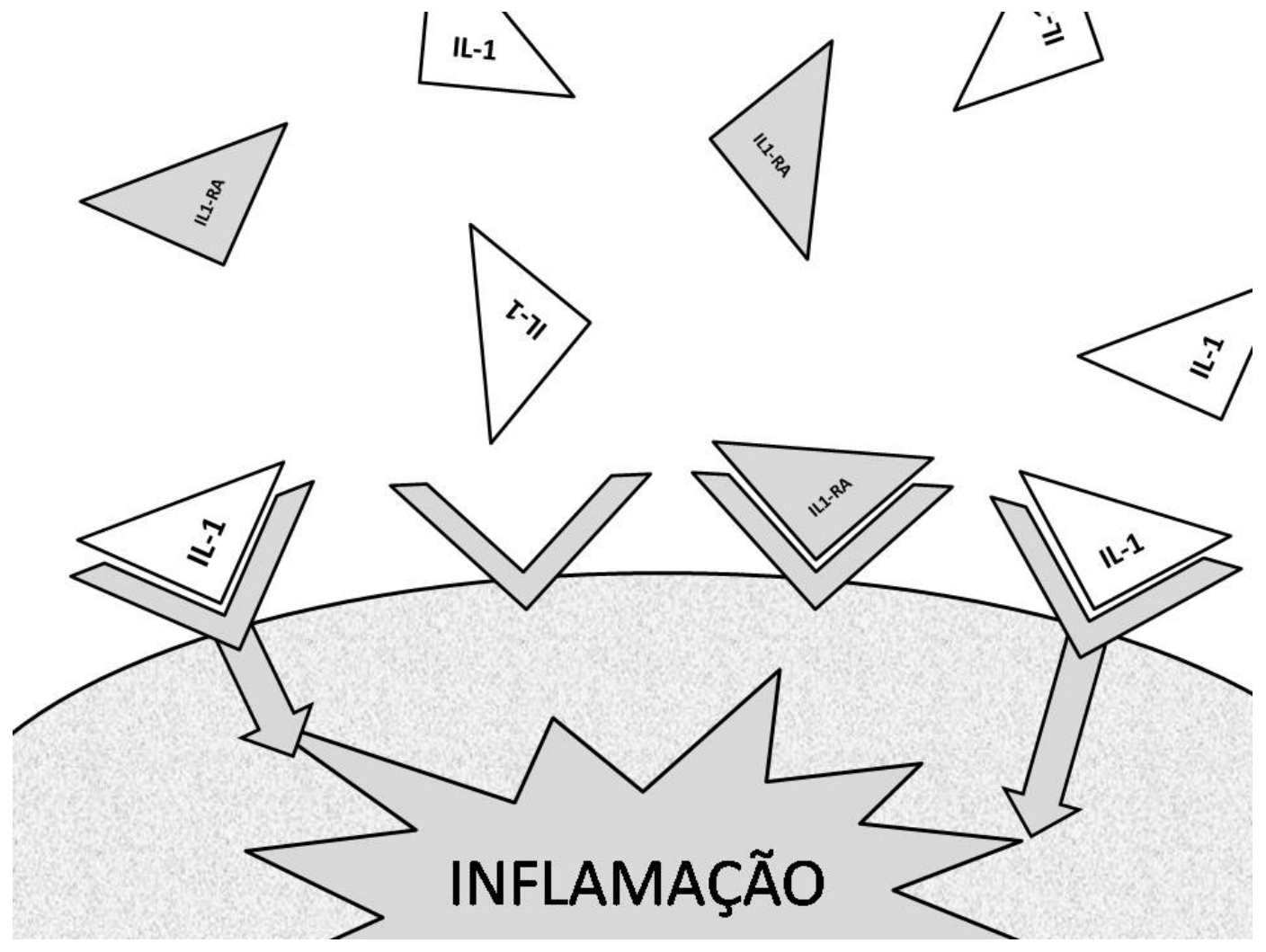

Figura 1. Interleucina-1, seu receptor e antagonista 
A concentração plasmática da interleucina-1 cresce precocemente após o estímulo inflamatório. Paralelamente aos seus efeitos próinflamatórios, a IL-1 estimula a secreção de seu antagonista principalmente por células mononucleares, iniciando uma alça de retroalimentação negativa que ajuda a sinalizar o término da resposta imune (gráfico 1). A razão IL1RA/IL-1 é importante na determinação da intensidade e duração da resposta inflamatória (Hirsch et al., 1996).

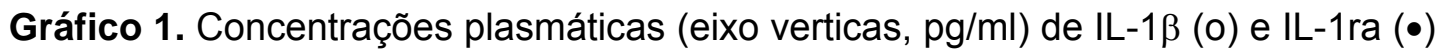
ao longo do tempo (eixo horizontal, horas), após endotoxemia experimental (Granowitz et al., 1991)

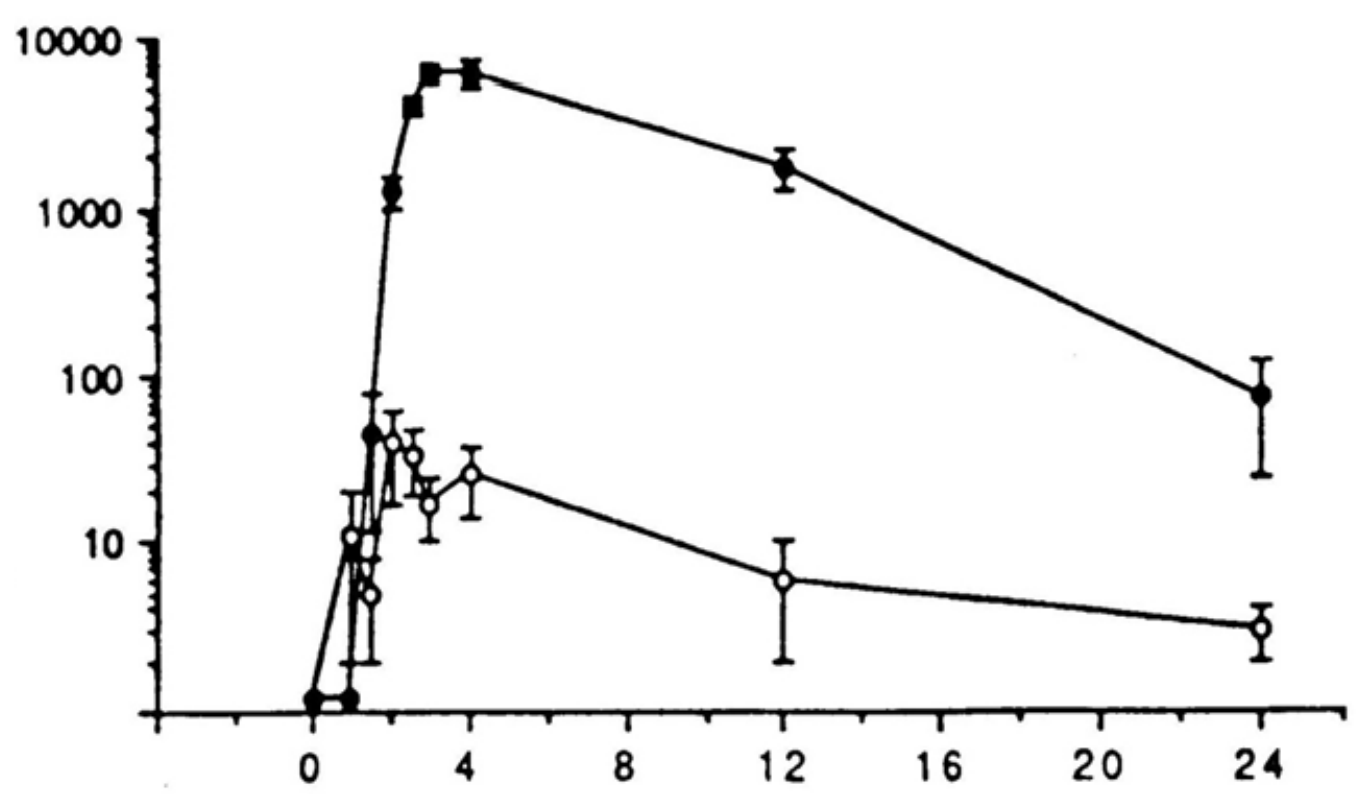


No segundo intron do gene codificador do IL-1ra existe uma seqüência de repetições tandem de 86 pares de bases. O número de vezes que esta seqüência é repetida varia de 2 a 6 (alelos 1 a 5). A freqüência destes alelos varia entre os diferentes grupos étnicos e geográficos, mas em todas as populações estudadas o alelo 1 (A1) foi sempre o mais comum, seguido pelo 2 (A2). Juntos, os demais alelos compreendem menos de $1 \%$ na maioria das populações. A prevalência de homozigotos para o IL1RN² é tipicamente menor que 10\% (Tabela 2).

Tabela 2. Alelos do IL1RN segundo o número de repetições em tandem de $86 \mathrm{pb}$ no íntron 2 e sua prevalência aproximada na população (Langdahl et al., 2000)

\begin{tabular}{ccc}
\hline Alelo & $\begin{array}{c}\text { No. Repetições em } \\
\text { Tandem Intron 2 }\end{array}$ & $\begin{array}{c}\text { Prevalência Aproximada } \\
\text { de Homozigotos }\end{array}$ \\
\hline 1 & 4 & $\sim 49 \%$ \\
2 & 2 & $<10 \%$ \\
3 & 3 & $<1 \%$ \\
4 & 5 & $<1 \%$ \\
5 & 6 & $<1 \%$ \\
\hline
\end{tabular}

Apesar de diversos polimorfismos terem sido descritos para o gene codificador do IL1-RA (IL1RN) (Clay et al., 1996; Langdahl et al., 2000), a maioria está em desequilíbrio de ligação, de forma a que o estudo de um único polimorfismo, a repetição em tandem de 86-pb no segundo intron do IL1RN é suficiente para avaliar apropriadamente a variação alélica do gene (Langdahl et al., 2000) (Figura 2). 


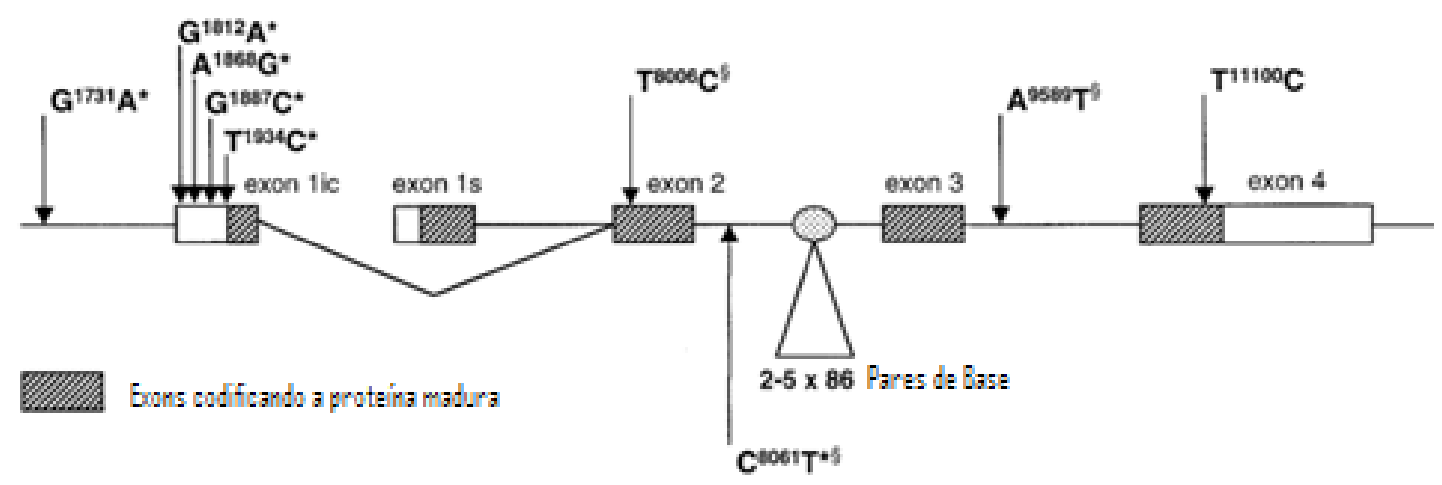

Figura 2. Estrutura do IL1RN com os diversos polimorfismos descritos (Langdahl et al., 2000)

Tem sido aceito que o número de repetições afeta a produção celular de IL1-RA, e que a variação alélica pode influenciar a concentração plasmática de IL1-RA e a resposta imune. A maioria dos estudos associa o alelo 2 a uma resposta imune exacerbada e o alelo 1 a um estado imunológico relativamente brando (Witkin et al., 2002). De fato, o A2 tem sido relacionado a um número de doenças inflamatórias e autoimunes, bem como a uma maior resistência a infecções (Witkin et al., 2002).

Considerando que a FR é uma doença inflamatória autoimune desencadeada por uma infecção bacteriana, avaliamos o polimorfismo do IL1RN com o intuito de determinar possível relevância na susceptibilidade à FR e suas manifestações clínicas. 


\section{OBJETIVOS}


a. Avaliar o polimorfismo do IL1RN como possível marcador de susceptibilidade à febre reumática,

b. Avaliar a presença do polimorfismo do IL1RN com as manifestações clínicas da febre reumática e gravidade de doença. 


\section{MÉTODOS}




\subsection{PARTICIPANTES}

Foram estudados 84 pacientes consecutivos com diagnóstico de FR que preencheram os critérios de Jones (Tabela 1) e tiveram o diagnóstico confirmado por pelo menos 3 anos de segmento ambulatorial na divisão de Reumatologia Pediátrica da Universidade de São Paulo, Brasil.

Os critérios de exclusão compreenderam história de doenças que pudessem causar dano cardíaco ou valvar (hipertensão, endocardite, doença de Chagas, uso de drogas ilícitas endovenosas), doenças psiquiátricas ou neurológicas, artrite idiopática juvenil, artrite reumatóide, lúpus e outras doenças inflamatórias.

Dados sobre as manifestações clínicas da FR foram obtidos por questionário padronizado e revisão extensa de prontuários. Cardite foi definida como sopro cardíaco novo detectado por médico treinado, com a correspondente estenose ou regurgitação valvar ao ecocardiograma. Artrite foi definida como dor, edema, calor, eritema ou limitação de movimento em grandes articulações, presenciados por reumatologista. Coréia foi definida como movimentos de tronco e/ou extremidades, rápidos, involuntários e despropositados, associados ou não a fraqueza muscular e labilidade emocional (1992). 
Todos os pacientes foram submetidos à ecocardiografia transtorácica em pelo menos duas ocasiões durante período de inatividade da doença. Cardite reumática foi graduada em grave ou moderada/leve e definida como grave se acompanhada de sintomas de insuficiência cardíaca congestiva (ICC), lesão valvar grave ao ecocardiograma, ou indicação de cirurgia valvar, esta última de acordo com as diretrizes do American College of Cardiology/American Heart Association, 1998 (Bonow et al., 1998). Cardite foi considerada leve/moderada na ausência de lesões valvares com repercussão hemodinamicamente significativas ou sintomas cardíacos.

Raça foi definida de acordo com a cor referida para os ascendentes de cada participante até a segunda geração, de acordo com método previamente validado para a população brasileira (Fuchs et al., 2002). A presença de afro-descendentes e caucasianos, ou de pardos entre os ascendentes, determinou a classificação como pardo. Na ausência de informações sobre os avôs, raça foi determinada pela raça referida para os pais. Descendentes das outras raças foram excluídos.

Oitenta e quatro doadores de sangue saudáveis do Hospital Bandeirantes, São Paulo, Brasil, com idade superior a 35 anos (com o intuito de minimizar a possibilidade de incluírem indivíduos que viessem a desenvolver FR) foram convidados a participar como controles. O critério de exclusão foi história de doença crônica ou recorrente.

O estudo foi aprovado por comissão de ética local, e os pacientes (ou seus responsáveis legais) e controles assinaram consenso informado. 


\subsection{DETERMINAÇÃO GENOTÍPICA DO IL1RN}

DNA genômico foi extraído de leucócitos periféricos por meio do kit GFX (Genomic Blood DNA Purification Kit - Amersham Bioscience, UK), segundo especificações do fabricante. A genotipagem foi realizada por meio de análise do número de repetições em tandem de $86 \mathrm{pb}$ no Segundo intron do IL1RN, de acordo com Tarlow et al. (Tarlow et al., 1993), utilizando-se sonda genética especifica (5'-ctc agc aac act cct at-3' and 5'-tcc tgg tct gca ggt aa-3'). Os produtos da amplificação genética por PCR (polymerase chain reaction) foram corados com brometo de etídio e visualizados em gel de agarose a $1 \%$ (Figura 3$)$

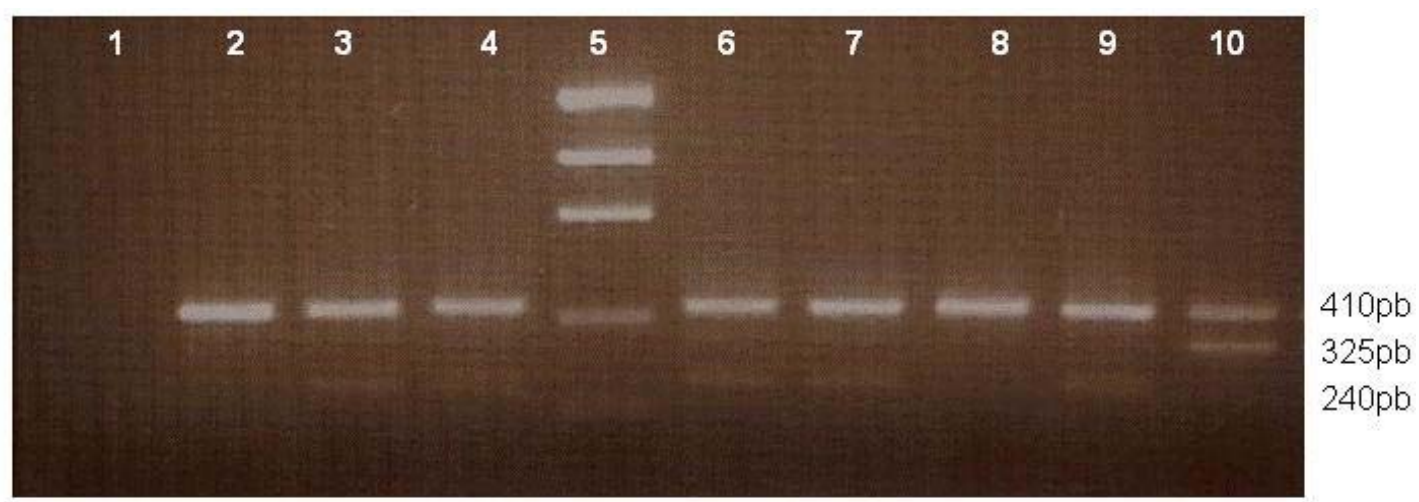

$\begin{array}{ccc}\text { Alelos } & \text { No Rep } & \text { No PB } \\ \text { A2 } & 2 & 240 \\ \text { A4 } & 3 & 325 \\ \text { A1 } & 4 & 410 \\ \text { A3 } & 5 & 500 \\ \text { A5 } & 6 & 595\end{array}$

Figura 3. Exemplo de visualização em gel de eletroforese do produto da amplificação do IL1RN por PCR 


\subsection{ANÁLISE ESTATÍSTICA}

Os dados foram analisados através do software SPSS 13.0 (SPSS Inc.). Foram calculadas a freqüência dos alelos (número de ocorrências do alelo na população estudada dividido pelo número total de alelos) e a taxa de porte (proporção de indivíduos que possuem uma ou mais cópias do alelo investigado). O equilibrio de Hardy-Weinberg foi testado para o polimorfismo do IL1RN usando o teste qui-quadrado. Para verificar a existência de associação entre as medidas observadas e a presença dos alelos foram também empregados testes qui-quadrado de homogeneidade (Agresti, 1990). Para cruzamentos de medidas incluindo menos de cinco indivíduos, usou-se o teste exato de Fisher. Um nível de significância de 5\% foi considerado estaticamente positivo. 
4. RESULTADOS 


\subsection{CARACTERÍSTICAS DOS PARTICIPANTES}

A idade dos pacientes variou de 7 a 41 anos (média de 18,6 anos), e a duração média de doença foi 9,4 anos (3-22). A distribuição racial nos 84 pacientes revelou clara predominância de caucasianos $(44 / 52,4 \%)$ e pardos $(38 / 45,2 \%)$ com uma pequena representação de afro-descendentes $(2 / 2,4 \%)$.

Cardite foi observada em $67(79,8 \%)$ pacientes. A maioria $(79,1 \%)$ foi classificada como leve/moderada e $14(20,9 \%)$ casos foram classificados como graves (Tabela 3). Todos os pacientes com cardite grave apresentaram sintomas de ICC e dez deles também com indicação cirúrgica. Lesão multivalvular (MVL) foi observada em 26 (38,8\%) pacientes: em um, 4 válvulas; em dois, 3 válvulas; e em vinte e três, 2 válvulas estavam acometidas. Os três pacientes com envolvimento de 3 ou 4 válvulas tinham doença cardíaca grave segundo os critérios adotados. A válvula mitral estava comprometida em 66 pacientes (98,5\%), a aórtica em 20 (29,8\%), a tricúspide em $9(13,4 \%)$ e a pulmonar em $1(1,5 \%)$.

As outras manifestações da FR observadas foram: artrite em 54 (64,3\%), coréia em $38(45,2 \%)$, eritema marginado em $9(10.7 \%)$, nódulos subcutâneos em 8 (1,2\%), artralgia em 63 (75,0\%), e febre em 58 (69,0\%). Dezessete $(20,2 \%)$ apresentaram apenas manifestações não cardíacas da FR (Tabela 3). 
Tabela 3. Características Clínicas dos pacientes com Febre Reumática

\begin{tabular}{|c|c|c|c|}
\hline \multicolumn{2}{|l|}{ Envolvimento Cardíaco } & \multicolumn{2}{|c|}{ Manifestações Não-Cardíacas } \\
\hline Cardite (\%) & $67(79,8)$ & Poliartrite (\%) & $54(64,3)$ \\
\hline Cardite Grave (\%) & $14(20,9)$ & Coréia (\%) & $38(45,2)$ \\
\hline $\begin{array}{l}\text { Indicação de Cirurgia Valvar } \\
(\%)\end{array}$ & $10(11,9)$ & Eritema Marginado (\%) & $9(10,7)$ \\
\hline Insuficiência Cardíaca (\%) & $14(20,9)$ & $\begin{array}{l}\text { Nódulos Subcutâneos } \\
(\%)\end{array}$ & $8(9,5)$ \\
\hline Lesão Multivalvar (\%) & $26(38,8)$ & Artralgia (\%) & $63(75)$ \\
\hline & & Febre (\%) & $58(69)$ \\
\hline
\end{tabular}

\subsection{RESULTADOS DA GENOTIPAGEM}

Oitenta e quatro pacientes com FR e 84 controles foram submetidos à análise dos alelos. Um total de 82 pacientes e 78 controles foi avaliado do ponto de vista genotípico, uma vez que apenas dois pacientes e cinco controles portavam o alelo A3, e 1 controle portava o A4 (genótipo A1/A4). Os genótipos A1/A3 e A1/A4 foram muito raros para que conclusões estatísticas fossem tiradas. Estas freqüências alélicas e genotípicas encontradas não estão em concordância com o equilíbrio genético de HardyWeinberg.

A taxa de porte para os alelos 1 e 2 foram comparáveis nos pacientes e controles $(p=0,188 ; p=0,106$, respectivamente) (Tabela 4). Cinqüenta e oito pacientes $(70,7 \%)$ foram homozigotos para o alelo 1 (A1/A1), cinco $(6,1 \%)$ foram homozigotos para o alelo 2 (A2/A2), e dezenove $(23,2 \%)$ 
possuíam o genótipo A1/A2. Dos 78 controles analisados, $44(56,4 \%)$ foram homozigotos para o alelo 1 (A1/A1), $10(12,8 \%)$ foram homozigotos para o alelo 2 (A2/A2), e $24(30,8 \%)$ apresentaram o genótipo A1/A2. Não houve diferença entre pacientes e controles em relação à freqüência genotípica $(p=0,131)($ Tabela 4).

Tabela 4. Taxa de porte para os alelos do ILIRN e freqüência genotípica em pacientes com Febre Reumática e controles normais

\begin{tabular}{lcccc}
\hline & & Febre Reumática & Controles & P \\
\cline { 3 - 5 } Alelo N (\%) & & $\mathrm{N}=84$ & $\mathrm{~N}=84$ & \\
\hline Alelo 1 & & & & \\
& Presente & $79(94,0)$ & $73(86,9)$ & 0,188 \\
Alelo 2 & Ausente & $5(6,1)$ & $11(13,1)$ & \\
& & & & 0,106 \\
& Presente & $24(28,6)$ & $35(41,7)$ & \\
\hline Genótipos N (\%) & $60(71,4)$ & $49(58,3)$ & \\
\hline & Ausente & $\mathrm{N}=82$ & $\mathrm{~N}=78$ & \\
& A1/A1 & $58(70,7)$ & $44(56,4)$ & \\
& A1/A2 & $19(23,2)$ & $24(30,8)$ & 0,131 \\
& A2/A2 & $5(6,1)$ & $10(12,8)$ &
\end{tabular}

A avaliação das diferentes manifestações clínicas da FR revelou uma menor taxa de porte e uma menor freqüência para o A1 entre os portadores de cardite grave do entre aqueles que não apresentaram essa manifestação 
$(\mathrm{OR}=0,11,95 \%$ IC: $0,016-0,72, p=0,031$ e $\mathrm{OR}=0,32,95 \%$ Cl: 0,129-0,783, respectivamente) (Tabela 5).

Tabela 5. Taxa de porte dos alelos e freqüência genotípica para o ILIRN em relação ao envolvimento cardíaco (Cardite e Cardite Grave) em pacientes com Febre Reumática

\begin{tabular}{l|ll|l}
\hline & \multicolumn{2}{|c|}{ Cardite } & \multicolumn{2}{c}{ Cardite Grave } \\
& Presente Ausente $\quad$ P & Presente Ausente P \\
\hline
\end{tabular}

Taxa de porte dos Alelos $n=84-n(\%)$

\begin{tabular}{|c|c|c|c|c|c|c|}
\hline \multicolumn{7}{|l|}{ Alelo 1} \\
\hline Presente & $62(92,5)$ & $\begin{array}{c}17 \\
(100,0)\end{array}$ & \multirow[t]{2}{*}{0,578} & $11(78,6)$ & $68(97,1)$ & \multirow[t]{2}{*}{0,031} \\
\hline Ausente & $5(7,5)$ & $0(0,0)$ & & $3(21,4)$ & $2(2,9)$ & \\
\hline \multicolumn{7}{|l|}{ Alelo 2} \\
\hline Presente & $20(29,9)$ & $4(23,5)$ & \multirow{2}{*}{0,767} & $7(50,0)$ & $17(24,3)$ & \multirow{2}{*}{0,101} \\
\hline Ausente & $47(70,1)$ & $13(76,5)$ & & $7(50,0)$ & $53(75,7)$ & \\
\hline \multicolumn{7}{|c|}{ Freqüência dos alelos n=168 } \\
\hline A1 & 106 & 31 & \multirow{2}{*}{0,451} & 18 & 119 & \multirow{2}{*}{0,016} \\
\hline A2 & 25 & 4 & & 10 & 21 & \\
\hline \multicolumn{7}{|c|}{ Genótipos n=82 - n (\%) } \\
\hline $\mathrm{A} 1 / \mathrm{A} 1 \mathrm{n}(\%)$ & $45(69,2)$ & $13(76,5)$ & \multirow{3}{*}{0,494} & $7(50,0)$ & $51(75,0)$ & \multirow{3}{*}{0,021} \\
\hline$A 1 / A 2 n(\%)$ & $15(23,1)$ & $4(23,5)$ & & $4(28,6)$ & $15(22,1)$ & \\
\hline $\mathrm{A} 2 / \mathrm{A} 2 \mathrm{n}(\%)$ & $5(7,7)$ & $0(0,0)$ & & $3(21,4)$ & $2(2,9)$ & \\
\hline
\end{tabular}

Semelhantemente, uma distribuição genotípica desigual (A1/A1 vs. $A 1 / A 2$ vs. $A 2 / A 2 ; p=0,021)$ foi observada neste grupo (Tabela 6 ), sendo que 
a proporção de pacientes com cardite grave foi menor nos pacientes com genótipo A1/A1 (7 em 58) do que nos pacientes com genótipo A2/A2 (3 em 5) $(\mathrm{OR}=0,092,95 \%$ IC: $0,013-0,65, \mathrm{p}=0,017)$. Nenhuma outra manifestação clínica foi associada a porte de alelo ou freqüência genotípica (Tabela 6).

Tabela 6. Taxa de porte e freqüência genotípica para o ILIRN em relação às manifestações não cardíacas nos pacientes com Febre Reumática

\begin{tabular}{|c|c|c|c|c|c|c|}
\hline & \multicolumn{3}{|c|}{ Poliartrite } & \multicolumn{3}{|c|}{ Coréia } \\
\hline & Presente & Ausente & $\mathbf{P}$ & Presente & Ausente & $\mathbf{P}$ \\
\hline \multicolumn{7}{|c|}{ Taxa de porte dos Alelos $n=84-n(\%)$} \\
\hline \multicolumn{7}{|l|}{ Alelo 1} \\
\hline $\begin{array}{l}\text { Presente } \\
\text { Ausente }\end{array}$ & $\begin{array}{c}52(96,3) \\
2(3,7)\end{array}$ & $\begin{array}{c}35(92,1) \\
3(7,9)\end{array}$ & 0,343 & $\begin{array}{c}35(92,1) \\
3(7,9)\end{array}$ & $\begin{array}{c}44(95,7) \\
2(4,3)\end{array}$ & 0,654 \\
\hline Alelo 2 & & & & & & \\
\hline $\begin{array}{l}\text { Presente } \\
\text { Ausente }\end{array}$ & $\begin{array}{l}13(24,1) \\
41(75,9)\end{array}$ & $\begin{array}{l}12(31,6) \\
26(68,4)\end{array}$ & 0,313 & $\begin{array}{l}12(31,6) \\
26(68,4)\end{array}$ & $\begin{array}{l}12(26,1) \\
34(73,9)\end{array}$ & 0,633 \\
\hline \multicolumn{7}{|c|}{ Freqüência dos alelos n=168 } \\
\hline $\begin{array}{l}\mathrm{A} 1 \\
\mathrm{~A} 2\end{array}$ & $\begin{array}{l}92 \\
15\end{array}$ & $\begin{array}{l}60 \\
15\end{array}$ & 0,314 & $\begin{array}{l}60 \\
15\end{array}$ & $\begin{array}{l}77 \\
14\end{array}$ & 0,539 \\
\hline \multicolumn{7}{|c|}{ Genótipo n=82 - n (\%) } \\
\hline $\mathrm{A} 1 / \mathrm{A} 1 \mathrm{n}(\%)$ & $40(75,0)$ & $25(68,0)$ & & $25(68,0)$ & $33(73,3)$ & \\
\hline $\mathrm{A} 1 / \mathrm{A} 2 \mathrm{n}(\%)$ & $11(20,8)$ & $9(24,3)$ & 0,336 & $9(24,3)$ & $10(22,3)$ & 0,748 \\
\hline A2/A2 n(\%) & $2(3,8)$ & $3(8,1)$ & & $3(8,1)$ & $2(4,4)$ & \\
\hline
\end{tabular}


5. DISCUSSÃO 
Este é o primeiro estudo que demonstrou a influência do polimorfismo do IL1RN em uma população brasileira de pacientes com FR, e encontrou uma associação negativa entre cardite grave (CG) e taxa de porte do A1 e o genótipo A1/A1. O resultado contrasta com os achados de Settin e cols. que demonstraram associação positiva entre o genótipo A1/A1, FR e lesão multivalvar (MVL) em 50 crianças egípcias (Settin et al., 2007). O critério usado para a definição de cardite grave pode, em parte, ser responsabilizado por esta diferença. Em nosso trabalho, lesão valvar grave, com repercussões hemodinâmicas significativas, insuficiência cardíaca congestiva ou indicação cirúrgica foram necessárias para definir cardite grave, o que provavelmente selecionou uma doença cardíaca mais agressiva.

Contudo, Chou e colaboradores não encontraram correlações entre os genótipos do IL1RN, FR ou MVL em 115 crianças chinesas de Taiwan (Chou et al., 2005). Estas disparidades ilustram a idéia de que a função de um gene é dependente do contexto no qual está inserido e que um mesmo gene pode ter diferentes expressões em diferentes raças. Esforços para associar FR com Antígenos Leucocitários Humanos (HLA) chegaram a diferentes resultados em diferentes populações (Guilherme et al., 2007) (tabela 7). Em alguns estudos, as associações variaram entre raças mesmo dentro de uma população especifica (Genc et al., 2002; Rider et al., 2000; Tountas et al., 1999; Witkin et al., 2001). 
A observação de que o A1 e o genótipo A1/A1 desempenham papel protetor contra cardite grave está em concordância com relatos prévios segundo os quais o $\mathrm{A} 1$ foi associado à uma resposta imune mais branda e o A2 à uma resposta mais agressiva (Witkin et al., 2002). Guilherme e colaboradores propuseram um modelo para a fisiopatologia da FR onde o mimetismo molecular inicia uma reação cruzada entre peptídeos derivados de Streptococcus do grupo A (principalmente resíduos $\mathrm{N}$-terminais de aminoácidos da proteína-M) e proteínas cardíacas, que leva ao dano cardíaco inicial. A destruição de tecidos do coração a leva à apresentação de antígenos usualmente escondidos, ao recrutamento e expansão policlonal de linfócitos e à exacerbação e perpetuação da autoimunidade e da subseqüente destruição tecidual (Guilherme \& Kalil, 2004). (Figura 4)

\section{Epitope Spreading}

\section{Mimetismo Molecular}

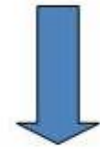

Autoimunidade

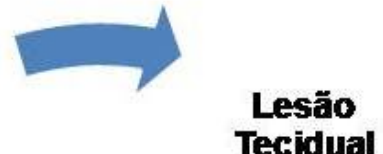

- Células T reconhecem de forma cruzada peptídeos derivados da proteína $\mathrm{M}$ e proteínas de tecidos cardíacos

- Expansão celular do tipo oligoclonal

Internal Arch Allergy Immunol 2004; 134: 56-64
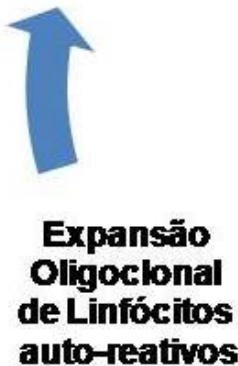

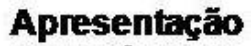
Deantigenos Teciduais
Tecidual

Figura 4. Modelo para a Fisiopatologia da febre reumática segundo Guilherme \& Kalil 
Neste modelo, a gravidade e perpetuação da reação autoimune tem um papel central, em conjunto com o mimetismo molecular. De fato, diversos dados sugerem que pacientes com FR apresentam uma resposta imune mais intensa e duradora. Os linfócitos de pacientes com febre reumática aguda têm reatividade celular exacerbada in vitro quando comparados àqueles de pacientes com gromerulonefrite pós-streptococica aguda, e esta reatividade tem seu pico de 1 a 6 meses após a infecção e dura até 2 anos (Jeremias et al., 1999). Quando estimuladas, células mononucleares derivadas de sangue periférico (PBMC) de pacientes com febre reumática aguda produzem maiores quantidades de IL-1 e IL-2 que PBMC de controles normais, pacientes com faringite estreptocócica (FE) ou cardite reumática crônica (CRC), e esta produção exagerada persiste após 48 semanas. As PBMC de pacientes com febre reumática aguda e cardite reumática aguda (CRA) também expressam maiores proporções de receptores de IL-2 (IL-2r), também conhecido como CD25. A IL-1 é considerada um amplificador da produção de IL-2 e IL-2r, e os autores especulam que a IL-1 é o principal fator responsável pela persistência do processo inflamatório (Morris et al., 1993). Em outro estudo, as concentrações plasmática de IL-1 e IL-2 foram maiores na febre reumática aguda do que na $\mathrm{FE}, \mathrm{CRC}$ ou em controles sadios, e a produção de IL-2 na febre reumática aguda e CRC correlacionaram-se diretamente com uma porcentagem aumentada de linfócitos CD4+ (T helper) e CD25+ (ativados) no sangue periférico (Narin et al., 1995). Os fatores responsáveis por esta imunidade exacerbada não são conhecidos. A análise do perfil de citoquinas in cito de células mononucleares infiltradas nos 
tecidos cardíacos e a análise da produção in vitro de citoquinas por linhagens de células T também infiltradas em tecidos cardíacos (válvulas versus átrio), ambas derivadas de pacientes com cardite reumática grave em suas fases aguda e crônica, sugeriu que a regressão da inflamação miocárdica não depende apenas da ação da interleucina 10 (IL-10), a interleucina regulatória predominante. A diferença observada nos tecidos derivados do átrio e das válvulas foram especulativamente atribuídas a células T auto-reativas imigrantes, quimiocinas de ação local e a diferentes expressões de moléculas de adesão. Embora a IL-1, ou seu antagonista, não tenham sidos testados, a predominância de interferon-gama (IFN-ү) e do fator de necrose tumoral alfa (TNF- $\alpha$ ) no coração sugerem que uma resposta tipo Th1 poderia mediar a doença reumática cardíaca. A produção de interleucina 4 (IL-4), uma citoquina tipo Th2, pareceu exercer um papel protetor (Guilherme et al., 2004). O fato de que, no presente estudo, o IL1RN tenha influenciado a cardite grave e não as demais manifestações da FR está em concordância com a hipótese de que apenas a cardite grave seja mediada por uma resposta Th1, com um predomínio de IL-1, IL-2 e TNF- $\alpha$ na fase aguda da doença. Artrite, coréia e as formas mais brandas de cardite parecem mediadas por uma resposta imune predominantemente do tipo Th2 (IL-4, IL-5, IL-6, IL-10 e IL-13)

Combinando análise imuno-histoquímica e morfologia comparativa, Fraser e colaboradores dividiram a progressão dos nódulos de Aschoff em três estágios: presença de macrófagos isolados, acumulação dos primeiros linfócitos Ts e, finalmente, o acúmulo de linfócitos B. Eles concluíram que a 
secreção macrofágica de IL-1 e TNF- $\alpha$ é necessária para a ativação e agregação de linfócitos $\mathrm{T}$ e $\mathrm{B}$, o que sugere que macrófagos chegariam à cena da lesão reumática antes dos linfócitos. IL-2 é usualmente expressa posteriormente e foi encontrada apenas em agregados linfóides (Fraser et al., 1997).

Combinado nossos resultados com os referidos dados sobre a FR, é possível postular um modelo no qual a imunidade cruzada inicial entre peptídeos estreptocócicos e proteínas cardíacas iniciariam um processo autoimune no coração que de outra forma seria auto-limitado se fatores genéticos e ambientais não determinassem uma reação imune mais agressiva, duradora e voltada para o tipo Th1. Os fatores levando para essa característica reação imune parecem agir precocemente no curso do processo inflamatório e também de forma importante localmente, a níveis parácrinos e autócrinos. Sendo que os monócitos e macrófagos são as primeiras células a chegar ao sítio inflamatório, é plausível que as citoquinas secretadas por estas células determinem o padrão da reação autoimune subseqüente através da promoção de moléculas de adesão, recrutamento e da ativação de linfócitos e promoção da apresentação de antígenos. A IL-1 e seu antagonista, o IL1-ra, são secretados precocemente por macrófagos intra-lesionais e a proporção entre estas duas citoquinas é importante para determinação da agressividade manutenção ou extinção da resposta imune (Hirsch et al., 1996). O polimorfismo do IL1RN influencia esta proporção e é provavelmente um dos fatores genéticos que influenciam a gravidade da doença cardíaca reumática. 
6. CONCLUSÃO 
Nossos dados indicam que o polimorfismo do IL1RN influencia a gravidade da manifestação cárdica em pacientes brasileiros com febre reumática. 
7. REFERÊNCIAS 
Guidelines for the diagnosis of rheumatic fever. Jones Criteria, 1992 update. Special Writing Group of the Committee on Rheumatic Fever, Endocarditis, and Kawasaki Disease of the Council on Cardiovascular Disease in the Young of the American Heart Association. JAMA1992; 268(15): 2069-73.

Agresti, A. Categorical Data Analysis. In: editor. New York: John Wiley and Sons; 1990. v., p. 558 pp

Ayoub, EM. Rheumatic Fever. In: editor. Clinical Immunology Principles \& Practice. Second. 2001. v. 6 (Systemic Immune Diseases), p. 1-7

Bonow, RO, B Carabello, AC de Leon, Jr., LH Edmunds, Jr., BJ Fedderly, MD Freed, WH Gaasch, CR McKay, RA Nishimura, PT O'Gara, RA O'Rourke, SH Rahimtoola, JL Ritchie, MD Cheitlin, KA Eagle, TJ Gardner, A Garson, Jr., RJ Gibbons, RO Russell, TJ Ryan , SC Smith, Jr.Guidelines for the management of patients with valvular heart disease: executive summary. A report of the American College of Cardiology/American Heart Association Task Force on Practice Guidelines (Committee on Management of Patients with Valvular Heart Disease). Circulation1998; 98(18): 1949-84.

Carapetis, JR, AC Steer, EK Mulholland, M Weber.The global burden of group A streptococcal diseases. Lancet Infect Dis2005; 5(11): 685-94.

Chou, HT, CH Tsai, WC Chen, FJ Tsai.Lack of association of genetic polymorphisms in the interleukin-1beta, interleukin-1 receptor antagonist, interleukin-4, and interleukin-10 genes with risk of rheumatic heart disease in Taiwan Chinese. Int Heart J2005; 46(3): 397-406.

Clay, FE, JK Tarlow, MJ Cork, A Cox, MJ Nicklin , GW Duff.Novel interleukin-1 receptor antagonist exon polymorphisms and their use in allele-specific mRNA assessment. Hum Genet1996; 97(6): 723-6. 
Cunningham, MW.Pathogenesis of group A streptococcal infections. Clin Microbiol Rev2000; 13(3): 470-511.

Fraser, WJ, Z Haffejee, D Jankelow, A Wadee , K Cooper.Rheumatic Aschoff nodules revisited. II: Cytokine expression corroborates recently proposed sequential stages. Histopathology1997; 31(5): 460-4.

Fuchs, SC, SM Guimaraes, C Sortica, F Wainberg, KO Dias, M Ughini, JA Castro, FD Fuchs.Reliability of race assessment based on the race of the ascendants: a cross-sectional study. BMC Public Health2002; 2: 1.

Genc, MR, S Gerber, M Nesin , SS Witkin.Polymorphism in the interleukin-1 gene complex and spontaneous preterm delivery. Am J Obstet Gynecol2002; 187(1): 157-63.

Granowitz, EV, AA Santos, DD Poutsiaka, JG Cannon, DW Wilmore, SM Wolff, CA Dinarello.Production of interleukin-1-receptor antagonist during experimental endotoxaemia. Lancet1991; 338(8780): 1423-4.

Gray, F, R Quinn , J WQuinn.A long term survey of rheumatic and non-rheumatic families; with particular reference to environment and heredity. Am J Med1952; 13(4): 400-12.

Guilherme, L, P Cury, LM Demarchi, V Coelho, L Abel, AP Lopez, SE Oshiro, S Aliotti, E Cunha-Neto, PM Pomerantzeff, AC Tanaka , J Kalil.Rheumatic heart disease: proinflammatory cytokines play a role in the progression and maintenance of valvular lesions. Am J Pathol2004; 165(5): 1583-91.

Guilherme, L , J Kalil.Rheumatic fever: from sore throat to autoimmune heart lesions. Int Arch Allergy Immunol2004; 134(1): 56-64.

Guilherme, L, R Ramasawmy , J Kalil.Rheumatic fever and rheumatic heart disease: genetics and pathogenesis. Scand J Immunol2007; 66(2-3): 199-207.

Hirsch, E, V Irikura, S Paul, D Hirsh.Functions of interleukin 1 receptor antagonist in gene knockout and overproducing mice. Proc Nat Acad Sci1996; 93: 11008-11013. 
Jeremias, J, P Giraldo, S Durrant, A Ribeiro-Filho, SS Witkin.Relationship between Ureaplasma urealyticum vaginal colonization and polymorphism in the interleukin-1 receptor antagonist gene. J Infect Dis1999; 180(3): 912-4.

Langdahl, BL, E Lokke, M Carstens, LL Stenkjaer , EF Eriksen.Osteoporotic fractures are associated with an 86-base pair repeat polymorphism in the interleukin-1--receptor antagonist gene but not with polymorphisms in the interleukin-1beta gene. J Bone Miner Res2000; 15(3): 402-14.

Morris, K, C Mohan, PL Wahi, IS Anand, NK Ganguly.Enhancement of IL-1, IL-2 production and IL-2 receptor generation in patients with acute rheumatic fever and active rheumatic heart disease; a prospective study. Clin Exp Immuno/1993; 91(3): 429-36.

Narin, N, N Kutukculer, R Ozyurek, AR Bakiler, A Parlar, M Arcasoy.Lymphocyte subsets and plasma IL-1 alpha, IL-2, and TNF-alpha concentrations in acute rheumatic fever and chronic rheumatic heart disease. Clin Immunol Immunopatho/1995; 77(2): 172-6.

Rider, LG, CM Artlett, CB Foster, A Ahmed, T Neeman, SJ Chanock, SA Jimenez , FW Miller.Polymorphisms in the IL-1 receptor antagonist gene VNTR are possible risk factors for juvenile idiopathic inflammatory myopathies. Clin Exp Immunol2000; 121(1): 47-52.

Settin, A, H Abdel-Hady, R El-Baz , I Saber.Gene Polymorphisms of TNF-alpha(308), IL-10 (-1082), IL-6 (-174), and IL-1Ra (VNTR) Related to Susceptibility and Severity of Rheumatic Heart Disease. Pediatr Cardiol2007; 28(5): 363-71.

Spagnuolo, M , A Taranta.Rheumatic fever in siblings. Similarity of its clinical manifestations. N Engl J Med1968; 278(4): 183-8.

Tarlow, JK, Al Blakemore, A Lennard, R Solari, HN Hughes, A Steinkasserer, GW Duff.Polymorphism in human IL-1 receptor antagonist gene intron 2 is caused by variable numbers of an 86-bp tandem repeat. Hum Genet1993; 91(4): 403-4. 
Tountas, NA, V Casini-Raggi, H Yang, FS Di Giovine, M Vecchi, L Kam, L Melani, TT Pizarro, JI Rotter , F Cominelli.Functional and ethnic association of allele 2 of the interleukin-1 receptor antagonist gene in ulcerative colitis. Gastroenterology1999; 117(4): 806-13.

Wilson, MG, M Schweitzer.Pattern of hereditary susceptibility in rheumatic fever. Circulation1954; 10(5): 699-704.

Witkin, SS, S Gerber, WJ Ledger.Influence of interleukin-1 receptor antagonist gene polymorphism on disease. Clin Infect Dis2002; 34(2): 204-9.

Witkin, SS, IM Linhares, S Gerber, ME Caetano , AC Segurado.Interleukin-1 receptor antagonist gene polymorphism and circulating levels of human immunodeficiency virus type 1 RNA in Brazilian women. J Virol2001; 75(13): 6242-4.

Zabriskie, JB.Rheumatic fever: the interplay between host, genetics, and microbe. Lewis A. Conner memorial lecture. Circulation1985; 71(6): 1077-86. 


\section{APÊNDICES}




\subsection{ARTIGO PARA PUBLICAÇÃO}

Interleukin-1 receptor antagonist gene (IL-1RN) polymorphism as a possible contributing factor for the severity of Rheumatic Carditis in a Brazilian cohort

Pedro Ming Azevedo ${ }^{a}$; Raquel Bauer ${ }^{a}$; Valeria de Falco Caparbo ${ }^{a}$; Clovis Artur Almeida Silva ${ }^{\text {; }}$ : Eloísa Bonfáa; Rosa Maria Rodrigues Pereira ${ }^{a}$.

${ }^{a}$ Rheumatology Division, Faculdade de Medicina da Universidade de Sao Paulo, Av. Dr. Arnaldo, 455 - Cerqueira Cesar - CEP: 01246903 - Sao Paulo - SP - Brasil Phone: +55 $113061-7000$.

${ }^{\mathrm{b}}$ Rheumatology Division, Instituto da Criança, Hospital das Clínicas of Sao Paulo, Av. Dr. Eneas Carvalho de Aguiar, 647, São Paulo - SP - Brazil CEP - 05403.000 Phone: +551130698500

Corresponding Author: Rosa Maria Rodrigues Pereira

E-mail: rosamariarp@yahoo.com

\section{Postal Address:}

Av. Dr. Arnaldo, 455, $3^{\circ}$ andar - Reumatologia - sala 3105

Cerqueira Cesar - São Paulo - Brazil

01246-903

Phonel Fax: +5511 3061 7490; 


\begin{abstract}
Aims: To evaluate the $I L-1 R N$ polymorphism as a possible marker for Rheumatic Fever (RF) susceptibility or disease severity.

Methods: The genotypes of $84 \mathrm{RF}$ patients (Jones criteria) and 84 normal racematched controls were determined through the analysis of the number of 86-bp tandem repeats in the second intron of $I L-1 R N$. The DNA was extracted from peripheral-blood leukocytes and amplified with specific primers. Clinical manifestations of RF were obtained through a standardized questionnaire and an extensive chart review. Carditis was defined as new onset cardiac murmur that was perceived by a trained physician with corresponding valvae regurgitation or stenosis on echocardiogram. Carditis was classified as severe in the presence of congestive heart failure or upon the indication for cardiac surgery. The statistical association among the genotypes, RF and its clinical variations was determined.
\end{abstract}

Results: The presence of allele 1 and the genotype A1/A1 were found less frequently among patients with severe carditis when compared to patients without this manifestation $(O R=0.11, p=0.031$; $O R=0.092, p=0.017)$. Neither allele 1 nor allele 2 were associated with the presence of $\operatorname{RF}(p=0.188 ; p=0.106)$, overall carditis $(p=0.578$ and $p=0.767)$, polyarthritis $(p=0.343$ and $p=0.313)$ and chorea $(p=0.654$ and $\mathrm{p}=0.633$ ).

Conclusion: In the Brazilian population, the polymorphism of the IL-1ra gene is a relevant factor for rheumatic heart disease severity.

Key words: IL1RN; Gene Polymorphism; Rheumatic Fever; Rheumatic Heart Disease. 


\section{Introduction}

Rheumatic Fever (RF) is a late consequence of a pharyngeal infection by Group $A$ Streptococcus. RF is still a great economical and social burden in developing countries, where the incidence remains close to 500,000 new cases each year [1]. The pathogenesis of RF is complex and mediated through both genetic and environmental factors [2]. It is estimated that only 0.3 to $3 \%$ of individuals who are known to be infected by rheumatogenic streptococcus will develop RF [2, 3] and that one- to two-thirds of these individuals will develop rheumatic carditis [4-6]. The factors that lead to the susceptibility to RF are not well understood, but patterns of familial aggregation $[7,8]$ and the stronger matching between identical over nonidentical twins, both argue in favor of a genetic influence [9]. In the same way, the similarities of RF manifestation in siblings may represent their genetic proximity [9].

On the other hand, it is well known that RF is an immune-mediated disease in which pro-inflammatory cytokines play an important role. Exacerbated Interleukin-1 (IL-1) production seems to be an early event in the immunological abnormalities that are observed in RF, which is subsequently followed by the production of Interleukin-2 (IL-2) [9]. The production IL-1 and IL-2 by peripheral mononuclear cells is exacerbated in acute RF patients when compared with Streptococcal pharyngitis or chronic latent RF patients [9].

The Interleukin-1 receptor antagonist (IL-1 ra) is an endogenous competitive inhibitor of IL-1 that acts by linking to the IL-1 receptor without initiating the intracellular cascade that leads to the inflammatory effects of the interleukins. The IL-1ra/IL-1 ratio is important in evaluating the intensity and duration of the inflammatory response [10].

Although many polymorphisms have been described for the IL-1ra gene $(I L 1 R N)[11,12]$, the majority are in linkage disequilibrium with each other, such that a single polymorphism, the 86 -bp tandem repeat in the second intron of ILIRN, is sufficient to evaluate the allelic variation of the gene [12]. It has been accepted that the number of repeats affects the cellular production of IL-1ra, and each allele may particularly influence the plasma concentration of IL-1ra and its immune response. The majority of studies associate A2 with an exacerbated inflammatory activity and A1 with a relatively mild inflammatory state [13]. In fact, A2 has been related to a number of inflammatory and autoimmune diseases as well as to a greater resistance to infections [13].

Considering that RF is an inflammatory autoimmune disease that is triggered by a bacterial infection, we have evaluated the $I L-1 R N$ polymorphism and its possible relevance to the susceptibility to RF and its clinical manifestations. 


\section{Materials and Methods}

\subsection{Subjects}

The study panel consisted of 84 consecutive chronic RF patients who fulfilled the Jones criteria and had their RF diagnosis confirmed by a follow-up after at least 3 years at the Pediatric Rheumatology Unit and Rheumatology Division, University of São Paulo, School of Medicine, Brazil. Exclusion criteria were a history of disease that may cause heart or valvular damage (such as hypertension, endocarditis, Chagas' disease and intravenous illicit drug use), neurological and psychiatric illnesses, juvenile idiopathic arthritis, rheumatoid arthritis and lupus and other inflammatory diseases.

Clinical manifestations of RF were obtained through a standardized questionnaire and an extensive chart review. Carditis was defined as new onset cardiac murmur that was perceived by a trained physician with corresponding valvae regurgitation or stenosis on echocardiogram. Arthritis was defined as tenderness, swelling, heat, redness or limitation of motion in the large joints, as determined by a rheumatologist. Chorea was defined as purposeless, involuntary, rapid movements of the trunk and/or extremities that may or may not be associated with muscle weakness and emotional lability [14].

All patients underwent transthoracic echocardiography on at least two occasions during periods of inactive disease, confirming or not the rheumatic heart disease. Heart rheumatic disease was graded as severe or mild/moderate. Carditis was defined as severe if accompanied by symptoms of congestive heart failure (CHF), a severe valvular lesion on echocardiography or the indication for valvular surgery, with the latter based upon the American College of Cardiology/American Heart Association 1998 Guidelines for the Management of Patients With Valvular Heart Disease [15]. Carditis was considered mild/moderate in patients without significant valvular hemodynamic impairment or heart symptoms.

Race was defined based on the self-reported race of ascendants until the second generation by each participant, as previously validated for the Brazilian population [16]. The presence of both Caucasian and African ascendants in a patient's heritage determined them as 'mixed race'. In the absence of information about the grandparents, race was determined by the race of the parents. Descendants of other races were excluded.

Eighty-four race-matched, healthy blood donors older than 35 years (to minimize the possibility of including individuals who were yet to show susceptibility to RF) from Hospital Bandeirantes (HB), São Paulo, Brazil, were invited to participate as controls. The exclusion criterion was a history of chronic or recurrent disease.

The study was approved by the Local Ethical Committee, and patients and controls (or their respective legal responsible) signed a consent form. 


\subsection{L-1RN Genotyping}

Genomic DNA was extracted from peripheral-blood leucocytes using the GFX Genomic Blood DNA Purification Kit (Amersham Bioscience, Little_Chalfont, UK), following specifications of the manufacturer. Genotyping was performed through the analysis of the number of 86-bp tandem repeats in $I L-1 R N$ intron 2, according to Tarlow et al. [17], using standard primers (5'-ctc agc aac act cct at-3' and 5'-tcc tgg tct gca ggt aa-3'). Ethidium bromide-stained polymerase chain reaction (PCR) products were visualized on a $1 \%$ agarose gel.

\subsection{Statistical analysis}

Data were analyzed using SPSS 13.0 software (SPSS Inc, Chicago, USA.). Allele frequencies (number of occurrences of the investigated allele in the population divided by the total number of alleles) and carriage rate (proportion of individuals who have at least one copy of the investigated allele) were calculated. HardyWeinberg equilibrium was tested for the IL1RN polymorphism using the $X^{2}-$ test. The $X^{2}$ statistic was also used to verify the existence of an association between the analyzed parameters and the presence of the alleles [18]. For $2 \times 2$ tables of data that included less than five individuals per cell, Fisher's exact test was used. A $5 \%$ significance level was considered to indicate statistical significance.

\section{Results}

\subsection{Patient characteristics}

The age of RF patients varied from 7 to 41 years old (median $=18.6$ ), and the median disease duration was 9.4 years (3-22). Race distribution in $84 \mathrm{RF}$ patients revealed a clear predominance of Caucasians (44/52.4\%) and mixed race $(38 / 45.2 \%)$, with a small representation of African descendants (2/2.4\%).

Carditis was observed in $67(79.8 \%)$ patients. The majority $(79.1 \%)$ of carditis was graded as mild/moderate, and $14(20.9 \%)$ cases were graded as severe (Table 1$)$. The severe carditis cases all had CHF symptoms, with ten of those also indicated for surgery. Multivalvar damage was observed in 26 (38.8\%) patients, with 1 patient having 4 damaged valves, 2 patients 3 damaged valves and 23 patients having 2 damaged valves. The three patients with three- or four-valve involvement had severe cardiac disease, as determined by the adopted criteria. The mitral valve was compromised in 66 patients $(98.5 \%)$, the aortic valve in $20(29.8 \%)$, the tricuspid valve in $9(13.4 \%)$ and the pulmonary valve in one $(1.5 \%)$.

The other clinical manifestations that were observed in RF were 54 (64.3\%) patients with polyarthritis, $38(45.2 \%)$ with chorea, $9(10.7 \%)$ with erythema marginatum, 8 
(1.2\%) with subcutaneous nodules, $63(75.0 \%)$ with arthralgia and $58(69.0 \%)$ with fever. Seventeen $(20.2 \%)$ had solely non-cardiac manifestations of RF (Table 1 ).

\subsection{Genotyping Results}

For the allelic analysis, a total of $84 \mathrm{RF}$ patients and 84 controls were evaluated. For genotype purposes, a total of 82 patients and 78 controls were evaluated, since two patients and five controls carried the $\mathrm{A} 3$ allele and one control carried an A4 allele (A1/A4 genotype). The genotypes A1/A3 and A1/A4 were too rare to draw statistical conclusions. These allele and genotype frequencies are not in accordance with Hardy-Weinberg of genetic equilibrium.

The $1 L-1 R N$ carriage rate for allele 1 (94 vs. $86.9 \%, p=0.188$ ) and allele 2 (28.6 vs. $41.7 \%, p=0.106$ ) was comparable in the RF and controls. Fifty-eight patients (70.7\%) were homozygous for allele 1 (A1/A1), five $(6.1 \%)$ were homozygous for allele 2 (A2/A2) and 19 (23.2\%) were heterozygous for alleles 1 and 2 (A1/A2). From the 78 controls who were analyzed, $44(56.4 \%)$ were homozygous for $A 1,10$ (12.8\%) were homozygous for A2 and $24(30.8 \%)$ were heterozygous for A1 and A2. No significant difference was observed between the patients and controls with regard to genotype frequency $(p=0.131)$.

The evaluation of the different clinical manifestations showed that the A1 allele was less carried $(\mathrm{OR}=0.11,95 \% \mathrm{Cl}: 0.016-0.72, p=0.031)$ and less frequent $(\mathrm{OR}=0.32,95 \% \mathrm{Cl}: 0.129-0.783, \mathrm{p}=0.016)$ in patients with severe carditis than in patients without this manifestation. Accordingly, an uneven genotype distribution ( $A 1 / A 1$ vs. $A 1 / A 2$ vs. $A 2 / A 2 ; p=0.021$ ) was observed in this group, with severe carditis being less frequent among those patients with the A1/A1 genotype (7 out of 58 ) than in those with the A2/A2 genotype (3 out of 5$)(\mathrm{OR}=0.092,95 \% \mathrm{Cl}: 0.013-$ $0.65, p=0.017)$. No other clinical manifestation was associated with allele carriage or genotype frequency (Table 3 ).

\section{Discussion}

This is the first study that demonstrates the influence of an IL-1RN polymorphism in RF for a Brazilian population, with a negative association being found between severe carditis and the $\mathrm{A} 1$ carriage rate and the A1/A1 genotype. This is in contrast to the findings of Settin et al., who demonstrated a positive association between the A1/A1 genotype, RF and multivalvar lesions (MVL) in 50 Egyptian children [19]. The criteria for the definition of severe carditis may, in part, account for this difference. In our work, severe valvar lesions with significant hemodynamic repercussions, 
congestive heart failure or surgery indication was necessary to define severe carditis, which probably selected for a more aggressive heart disease.

However, Chou et al. found no statistical correlation between the IL-1RN genotypes, RF or MVL in 115 Chinese children from Taiwan [20]. These disparities illustrate the idea that the function of a gene is dependent on its genomic context and that the same gene may have different expression patterns in different races. Efforts directed towards associating RF with specific Human Leukocyte Antigens (HLA) have led to different results in different populations [4]. In some studies, the associations varied between races within a specific population [21-24].

The observation that $\mathrm{A} 1$ and $\mathrm{A} 1 / \mathrm{A} 1$ have a protective effect against severe carditis is in agreement with previous reports in which the A1 allele was associated with a milder immune response and the A2 allele with a more aggressive response [13]. Guilherme et al. proposed a model of RF physiopathology in which molecular mimicry triggers a cross-reaction between group A Streptococcus peptides (mainly the $\mathrm{N}$-terminal amino acid residues of the M-protein) and heart proteins, which leads to initial heart damage, tissue destruction, the presentation of usually hidden heart antigens, polyclonal lymphocyte recruitment and expansion and an enhancement and perpetuation of autoimmunity and its subsequent tissue destruction [25]. In this model, the severity and perpetuation of the autoimmune reaction plays a central role, along with molecular mimicry. In fact, several observations suggest that RF patients have a more severe and long-lasting immune reaction. The lymphocytes of acute RF (ARF) patients have exacerbated in vitro cellular reactivity as compared to those patients with acute post-streptococcal glomerulonephritis; this reactivity peaks at 1 to 6 months after onset and lasts for at least 2 years [26]. When stimulated, the peripheral blood mononuclear cells (PBMC) of ARF patients produced larger amounts of IL-1 and IL-2 than do PBMCs from normal controls, streptococcal pharyngitis (SP) patients or chronic rheumatic heart disease (CRHD) patients. This IL-2 overproduction persists after 48 weeks. The PBMCs of ARF and acute rheumatic heart disease (ARHD) patients also express higher proportions of IL-2 receptors (CD25). IL-1 is considered to be an amplifier of IL-2 and IL-2r production, and the authors speculated that IL-1 is the major factor that is responsible for the persistent inflammatory process [26]. In another study, the plasma concentration of IL-1 and IL-2 were higher in ARF than in SP, CRHD or normal control samples, and the production of IL-2 in ARF and CRHD directly correlated with increased percentages of CD4+ (T helper) and CD25+ cells in the peripheral blood [27].

The factors behind this exacerbated immunity in RF are not known. The analysis of the in situ cytokine profile of heart-infiltrating mononuclear cells and the cytokine pattern produced in vitro by heart-infiltrating T-cell lines (HILs) from the heart tissue (valvar versus atrium) of severe RHD patients in the acute or chronic phases of the disease suggested that Th1-type cytokines could mediate RHD. The production of IL-4 (a Th2-type cytokine) seemed to play a protective role [28]. In the same way, the fact that, in this study, IL-1RN influenced severe carditis but not the other manifestations of RF is in agreement with the hypothesis that only severe carditis is mainly mediated through a Th-1 immune response, with a preponderance of IL-1, IL- 
2 and TNF- $\alpha$ being available in the acute phase of the disease. Arthritis, chorea and the milder forms of carditis seem to be associated with a preponderance of the Th-2 type immune response (IL-4, IL-5, IL-6, IL-10 and IL-13) [2, 29].

Combining immuno-histochemical analysis with comparative morphology, Fraser et al. divided the progression of the Aschoff nodules into three chronologic stages, which were macrophages only, accumulation of first $T$ lymphocytes and finally the accumulation of B lymphocytes. They concluded that IL-1 and TNF- $\alpha$ secretion in macrophages is required for $T$ and $B$ lymphocyte activation and aggregation, which suggests that the macrophages arrive at the scene of rheumatic injury prior to lymphocytes. IL-2 is usually expressed later and was found only in the lymphoid aggregates [30].

Combining our results with the previous RF data, it is possible to postulate a model in which the initial immune cross-reaction between Streptococcus peptides and heart proteins triggers an autoimmune process in the heart that would otherwise be self-limited, if genetic and environmental factors did not determine a stronger, longer and more Th1-type oriented immune reaction. The factors leading to this characteristic immune reaction seem to act early in the course of the inflammation process, as well as locally, at the paracrine and autocrine level. Since monocytes and macrophages are the first cells to arrive at the inflammation site, it is plausible that the cytokines that are secreted by these cells determine the pattern of the subsequent immune reaction through the promotion of adhesion molecules, lymphocyte recruitment and activation and the promotion of antigen presentation. IL1 and its antagonist, IL-1ra, are secreted early by intra-lesional macrophages, and the proportion of these two cytokines is important for the determination of the maintenance or extinction of the immune response [10]. The IL-1RN polymorphism influences this proportion and is likely to be one of the genetic factors that influence the severity of rheumatic heart disease.

In conclusion, our data indicate that this $I L-1 R N$ polymorphism may influence the severity of the heart manifestation in Brazilian RF patients.

\section{Acknowledgements:}

We deeply thank Dr. Luiza Guilherme for her help and support in the discussion.

Grants Support: CNPQ \# 305691/2006 (to RMRP); CNPQ \# 304756/2003-2 and Federico Foundation Wilhelm Agricola Research Grants (to EB). 


\section{References:}

1. Carapetis JR, Steer AC, Mulholland EK Weber M. The global burden of group A streptococcal diseases. Lancet Infect Dis 2005; 5(11):685-94.

2. Ayoub EM, Rheumatic Fever, in Clinical Immunology Principles \& Practice. 2001. p. 1-7.

3. Rheumatic fever and rheumatic heart disease. World Health Organ Tech Rep Ser 2004; 923:1-122, back cover.

4. Guilherme L, Ramasawmy R Kali J. Rheumatic fever and rheumatic heart disease: genetics and pathogenesis. Scand J Immunol 2007; 66(2-3):199-207.

5. Carapetis JR, Currie BJ Mathews JD. Cumulative incidence of rheumatic fever in an endemic region: a guide to the susceptibility of the population? Epidemiol Infect 2000; 124(2):239-44.

6. Caldas AM, Terreri MT, Moises VA, Silva CM, Len CA, Carvalho AC, et al. What is the true frequency of carditis in acute rheumatic fever? A prospective clinical and Doppler blind study of 56 children with up to 60 months of followup evaluation. Pediatr Cardiol 2008; 29(6):1048-53.

7. Wilson MG Schweitzer M. Pattern of hereditary susceptibility in rheumatic fever. Circulation 1954; 10(5):699-704.

8. Gray F, Quinn R WQuinn J. A long term survey of rheumatic and nonrheumatic families; with particular reference to environment and heredity. Am J Med 1952; 13(4):400-12.

9. Spagnuolo M Taranta A. Rheumatic fever in siblings. Similarity of its clinical manifestations. N Engl J Med 1968; 278(4):183-8.

10. Hirsch E, Irikura V, Paul S Hirsh D. Functions of interleukin 1 receptor antagonist in gene knockout and overproducing mice. Proc Nat Acad Sci 1996; 93:11008-13.

11. Clay FE, Tarlow JK, Cork MJ, Cox A, Nicklin MJ Duff GW. Novel interleukin1 receptor antagonist exon polymorphisms and their use in allele-specific mRNA assessment. Hum Genet 1996; 97(6):723-6.

12. Langdahl BL, Lokke E, Carstens M, Stenkjaer LL Eriksen EF. Osteoporotic fractures are associated with an 86-base pair repeat polymorphism in the interleukin-1--receptor antagonist gene but not with polymorphisms in the interleukin-1beta gene. J Bone Miner Res 2000; 15(3):402-14.

13. Witkin SS, Gerber S Ledger WJ. Influence of interleukin-1 receptor antagonist gene polymorphism on disease. Clin Infect Dis 2002; 34(2):204-9.

14. Guidelines for the diagnosis of rheumatic fever. Jones Criteria, 1992 update. Special Writing Group of the Committee on Rheumatic Fever, Endocarditis, and Kawasaki Disease of the Council on Cardiovascular Disease in the Young of the American Heart Association. JAMA 1992; 268(15):2069-73. 
15. Bonow RO, Carabello B, de Leon AC, Jr., Edmunds LH, Jr., Fedderly BJ, Freed $\mathrm{MD}$, et al. Guidelines for the management of patients with valvular heart disease: executive summary. A report of the American College of Cardiology/American Heart Association Task Force on Practice Guidelines (Committee on Management of Patients with Valvular Heart Disease). Circulation 1998; 98(18):1949-84.

16. Fuchs SC, Guimaraes SM, Sortica C, Wainberg F, Dias KO, Ughini M, et al. Reliability of race assessment based on the race of the ascendants: a crosssectional study. BMC Public Health 2002; 2:1.

17. Tarlow JK, Blakemore Al, Lennard A, Solari R, Hughes HN, Steinkasserer A, et al. Polymorphism in human IL-1 receptor antagonist gene intron 2 is caused by variable numbers of an 86 -bp tandem repeat. Hum Genet 1993; 91(4):403-4.

18. Agresti A, Categorical Data Analysis. 1990, John Wiley and Sons: New York. p. 558pp.

19. Settin A, Abdel-Hady H, El-Baz R Saber I. Gene Polymorphisms of TNFalpha(-308), IL-10 (-1082), IL-6 (-174), and IL-1Ra (VNTR) Related to Susceptibility and Severity of Rheumatic Heart Disease. Pediatr Cardiol 2007; 28(5):363-71.

20. Chou HT, Tsai $\mathrm{CH}$, Chen WC Tsai FJ. Lack of association of genetic polymorphisms in the interleukin-1beta, interleukin-1 receptor antagonist, interleukin-4, and interleukin-10 genes with risk of rheumatic heart disease in Taiwan Chinese. Int Heart J 2005; 46(3):397-406.

21. Rider LG, Artlett CM, Foster CB, Ahmed A, Neeman T, Chanock SJ, et al. Polymorphisms in the IL-1 receptor antagonist gene VNTR are possible risk factors for juvenile idiopathic inflammatory myopathies. Clin Exp Immunol 2000; 121(1):47-52.

22. Genc MR, Gerber S, Nesin M Witkin SS. Polymorphism in the interleukin-1 gene complex and spontaneous preterm delivery. Am J Obstet Gynecol 2002; 187(1):157-63.

23. Witkin SS, Linhares IM, Gerber S, Caetano ME Segurado AC. Interleukin-1 receptor antagonist gene polymorphism and circulating levels of human immunodeficiency virus type 1 RNA in Brazilian women. J Virol 2001; 75(13):6242-4.

24. Tountas NA, Casini-Raggi V, Yang H, Di Giovine FS, Vecchi M, Kam L, et al. Functional and ethnic association of allele 2 of the interleukin-1 receptor antagonist gene in ulcerative colitis. Gastroenterology 1999; 117(4):806-13.

25. Guilherme $L$ Kalil J. Rheumatic fever: from sore throat to autoimmune heart lesions. Int Arch Allergy Immunol 2004; 134(1):56-64.

26. Morris K, Mohan C, Wahi PL, Anand IS Ganguly NK. Enhancement of IL-1, IL-2 production and IL-2 receptor generation in patients with acute rheumatic fever and active rheumatic heart disease; a prospective study. Clin Exp Immunol 1993; 91(3):429-36. 
27. Narin N, Kutukculer N, Ozyurek R, Bakiler AR, Parlar A Arcasoy M. Lymphocyte subsets and plasma IL-1 alpha, IL-2, and TNF-alpha concentrations in acute rheumatic fever and chronic rheumatic heart disease. Clin Immunol Immunopathol 1995; 77(2):172-6.

28. Guilherme L, Cury P, Demarchi LM, Coelho V, Abel L, Lopez AP, et al. Rheumatic heart disease: proinflammatory cytokines play a role in the progression and maintenance of valvular lesions. Am J Pathol 2004; 165(5):1583-91.

29. Cunningham MW. Pathogenesis of group A streptococcal infections. Clin Microbiol Rev 2000; 13(3):470-511.

30. Fraser WJ, Haffejee Z, Jankelow D, Wadee A Cooper K. Rheumatic Aschoff nodules revisited. II: Cytokine expression corroborates recently proposed sequential stages. Histopathology 1997; 31(5):460-4. 


\subsection{NORMAS DA REVISTA}

\section{Guide for Authors}

Official journal of the International Cytokine Society

Ensure that the following items are present:

One Author designated as corresponding Author:

- E-mail address

- Full postal address

- Telephone and fax numbers

All necessary files have been uploaded

- Keywords

- All figure captions

- All tables (including title, description, footnotes)

\section{Further considerations}

- Manuscript has been "spellchecked"

- References are in the correct format for this journal

- All references mentioned in the Reference list are cited in the text, and vice versa

- Permission has been obtained for use of copyrighted material from other sources (including the Web)

- Colour figures are clearly marked as being intended for colour reproduction on the Web (free of charge) and in print or to be reproduced in colour on the Web (free of charge) and in black-and-white in print

- If only colour on the Web is required, black and white versions of the figures are also supplied for printing purposes

\section{Submission of articles}

\section{General}

Articles must be written in English.

It is essential to give a fax number and e-mail address when submitting a manuscript. Articles must be written in good English.

Submission of an article implies that the work described has not been published previously (except in the form of an abstract or as part of a published lecture or academic thesis), that it is not under consideration for publication elsewhere, that its publication is approved by all authors and tacitly or explicitly by the responsible authorities where the work was carried out, and that, if accepted, it will not be published elsewhere in the same form, in English or in any other language, without the written consent of the Publisher. 
Elsevier facilitates author response to the NIH voluntary posting request (referred to as the NIH "Public Access Policy", see at http://www.nih.gov/about/publicaccess/index.htm) by posting the peer-reviewed author's manuscript directly to PubMed Central on request from the author, 12 months after formal publication. Upon notification from Elsevier of acceptance, we will ask you to confirm via e-mail (by e-mailing us at NIHauthorrequest@elsevier.com) that your work has received NIH funding and that you intend to respond to the NIH policy request, along with your NIH award number to facilitate processing. Upon such confirmation, Elsevier will submit to PubMed Central on your behalf a version of your manuscript that will include peer-review comments, for posting 12 months after formal publication. This will ensure that you will have responded fully to the NIH request policy. There will be no need for you to post your manuscript directly with PubMed Central, and any such posting is prohibited.

Submission to this journal proceeds totally online. Use the following guidelines to prepare your article. Via the journal homepage athttp://ees.elsevier.com/ycyto/ you will be guided stepwise through the creation and uploading of the various files. The system automatically converts source files to a single Adobe Acrobat PDF version of the article, which is used in the peer-review process. Please note that even though manuscript source files are converted to PDF at submission for the review process, these source files are needed for further processing after acceptance. All correspondence, including notification of the Editor's decision and requests for revision, takes place by e-mail and via the Author's homepage, removing the need for a hard-copy paper trail.

The above represents a very brief outline of this form of submission. It can be advantageous to print this "Guide for Authors" section from the site for reference in the subsequent stages of article preparation.

\section{Referee recommendations and negative preference}

Please submit, with the manuscript, the names and addresses (including contact email addressess) of a minimum of 5 people suggested as reviewers for your manuscript. Please include reviewers who are independent and unbiased, from different institutions. You may also mention persons who you would prefer not to review your paper.

\section{Electronic format requirements for accepted articles}

We accept most wordprocessing formats, but Word or WordPerfect is preferred. Always keep a backup copy of the electronic file for reference and safety. Save your files using the default extension of the program used.

\section{Wordprocessor documents}

It is important that the file be saved in the native format of the wordprocessor used. The text should be in single-column format. Keep the layout of the text as simple as 
possible. Most formatting codes will be removed and replaced on processing the article. In particular, do not use the wordprocessor's options to justify text or to hyphenate words. However, do use bold face, italics, subscripts, superscripts etc. Do not embed "graphically designed" equations or tables, but prepare these using the wordprocessor's facility. When preparing tables, if you are using a table grid, use only one grid for each individual table and not a grid for each row. If no grid is used, use tabs, not spaces, to align columns. The electronic text should be prepared in a way very similar to that of conventional manuscripts.

Do not import the figures into the text file but, instead, indicate their approximate locations directly in the electronic text and on the manuscript. See also the section on Preparation of electronic illustrations.

To avoid unnecessary errors you are strongly advised to use the "spellchecker" function of your wordprocessor.

\section{Disclaimer}

Although Elsevier can process most wordprocessor file formats, should your electronic file prove to be unusable, the article will be typeset from the hardcopy printout.

\section{Presentation of manuscript}

\section{General}

Please write your text in good English (American or British usage is accepted, but not a mixture of these). Italics are not to be used for expressions of Latin origin, for example, in vivo, et al., per se. Use decimal points (not commas); use a space for thousands (10 000 and above).

Help with English text for non-English-speaking Authors.

\section{Language Polishing.}

For authors who require information about language editing and copyediting services pre- and post-submission please visit http://www.elsevier.com/wps/find/authorshome.authors/languagepolishing or contact authorsupport@elsevier.com for more information. Please note Elsevier neither endorses nor takes responsibility for any products, goods or services offered by outside vendors through our services or in any advertising. For more information please refer to our Terms \& Conditions: http://www.elsevier.com/wps/find/termsconditions.cws_home/termsconditions Text Page.

Provide the following data on the title page (in the order given).

Author names and affiliations.

Where the family name may be ambiguous (e.g., a double name), please indicate this clearly. Present the Authors' affiliation addresses (where the actual work was done) below the names. Indicate all affiliations with a lower-case superscript letter immediately after the Author's name and in front of the appropriate address. Provide 
the full postal address of each affiliation, including the country name, and, if available, the e-mail address of each Author.

\section{Corresponding Author.}

Clearly indicate who is willing to handle correspondence at all stages of refereeing and publication, also post-publication. Ensure that telephone and fax numbers (with country and area code) are provided in addition to the e-mail address and the complete postal address.

\section{Present/permanent address.}

If an Author has moved since the work described in the article was done, or was visiting at the time, a "Present address"' (or "Permanent address") may be indicated as a footnote to that Author's name. The address at which the Author actually did the work must be retained as the main, affiliation address. Superscript Arabic numerals are used for such footnotes.

\section{Abstract.}

A concise and factual abstract is required (maximum length 200 words). The abstract should state briefly the purpose of the research, the principal results and major conclusions. An abstract is often presented separate from the article, so it must be able to stand alone.

References should be avoided, but if essential, they must be cited in full, without reference to the reference list.

Non-standard or uncommon abbreviations should be avoided, but if essential they must be defined at their first mention in the abstract itself.

Keywords.

Immediately after the abstract, provide a maximum of 5 keywords, avoiding general and plural terms and multiple concepts (avoid, for example, "and", "of"). Be sparing with abbreviations: only abbreviations firmly established in the field may be eligible. These keywords will be used for indexing purposes.

Abbreviations.

Define abbreviations that are not standard in this field at their first occurrence in the article: in the abstract but also in the main text after it. Ensure consistency of abbreviations throughout the article.

\section{N.B. Acknowledgements.}

Collate acknowledgements in a separate section at the end of the article and do not, therefore, include them on the title page, as a footnote to the title or otherwise.

Subdivision of the article.

Divide your article into clearly defined and numbered sections. Subsections should be numbered 1.1 (then 1.1.1,1.1.2,), 1.2, etc. (the abstract is not included in section numbering). Use this numbering also for internal cross-referencing: do not just refer 
to "the text". Any subsection may be given a brief heading. Each heading should appear on its own separate line.

Introduction.

State the objectives of the work and provide an adequate background, avoiding a detailed literature survey or a summary of the results.

Materials and methods.

Provide sufficient detail to allow the work to be reproduced. Methods already published should be indicated by a reference: only relevant modifications should be described.

Results.

Results should be clear and concise.

Discussion.

This should explore the significance of the results of the work, not repeat them.

Acknowledgements.

Place acknowledgements, including information on grants received, before the references, in a separate section, and not as a footnote on the title page.

References.

See separate section, below.

Tables.

Number tables consecutively in accordance with their appearance in the text. Place footnotes to tables below the table body and indicate them with superscript lowercase letters. Avoid vertical rules. Be sparing in the use of tables and ensure that the data presented in tables do not duplicate results described elsewhere in the article.

Nomenclature and units.

Follow internationally accepted rules and conventions: use the international system of units (SI). If other quantities are mentioned, give their equivalent in SI. You are urged to consult

IUB: Biochemical Nomenclature and Related Documents: http://www.chem.qmw.ac.uk/iubmb/ for further information.

GenBank/DNA sequence linking

For each and every accession number cited in an article, Authors should type the accession number in bold, underlined text. Letters in the accession number should always be capitalised. (See Example below). This combination of letters and format will enable Elsevier's typesetters to recognise the relevant texts as accession numbers and add the required link to GenBank's sequences. Example: "GenBank accession nos. Al631510 , Al631511, Al632198, and BF223228) , a B-cell tumor from a chronic lymphatic leukemia (GenBank accession no. BE675048), and a T-cell lymphoma (GenBank accession no. AA361117) ". 
Authors are encouraged to check accession numbers used very carefully. An error in a letter or number can result in a dead link. In the final version of the printed article, the accession number text will not appear bold or underlined. In the final version of the electronic copy, the accession number text will be linked to the appropriate source in the $\mathrm{NCBI}$ databases enabling readers to go directly to that source from the article.

\section{Supplementary material submission on line}

Preparation of supplementary data. Elsevier now accepts electronic supplementary material (e-components) to support and enhance your scientific research. Supplementary files offer the Author additional possibilities to publish supporting applications, movies, animation sequences, high-resolution images, background datasets, sound clips and more. Supplementary files supplied will be published online alongside the electronic version of your article in Elsevier Web products, including ScienceDirect: -http://www.sciencedirect.com. In order to ensure that your submitted material is directly usable, please ensure that data is provided in one of our recommended file formats. Authors should submit the material in electronic format together with the article and supply a concise and descriptive caption for each file. For more detailed instructions about submitting electronic artwork/files, please visit athttp://authors.elsevier.com/artwork.

This journal offers electronic submission services and supplementary data files can be uploaded via the homepage of the journal at ${ }^{\prime}$ http://ees.elsevier.com/ycyto/.

Policy and ethics.

The work described in your article must have been carried out in accordance with The Code of Ethics of the World Medical Association (Declaration of Helsinki) for experiments involving humans; http://www.wma.net/e/policy/b3.htm

EC Directive 86/609/EEC for animal experiments; http://europa.eu.int/scadplus/leg/en/s23000.htm

Uniform Requirements for manuscripts submitted to Biomedical journals: $\square$ http://www.nejm.org/general/text/requirements/1.htm This must be stated at an appropriate point in the article.

\section{References}

Responsibility for the accuracy of bibliographic citations lies entirely with the Authors.

\section{Citations in the text:}

Please ensure that every reference cited in the text is also present in the reference list (and vice versa). Any references cited in the abstract must be given in full. Unpublished results and personal communications are not recommended in the reference list, but may be mentioned in the text. If these references are included in the reference list they should follow the standard reference style of the journal and should include a substitution of the publication date with either "Unpublished results" or "Personal communication" Citation of a reference as "in press" implies that the 
item has been accepted for publication and a copy of the title page of the relevant article must be submitted.

Citing and listing of Web references.

As a minimum, the full URL should be given. Any further information, if known (Author names, dates, reference to a source publication, etc.), should also be given. Web references can be listed separately (e.g., after the reference list) under a different heading if desired, or can be included in the reference list.

Text:

Indicate references by number(s) in square brackets in line with the text. The actual Authors can be referred to, but the reference number(s) must always be given. List: Number the references (numbers in square brackets) in the list in the order in which they appear in the text.

Examples:

Reference to a journal publication:

[1] Van der Geer J, Hanraads JAJ, Lupton RA. The art of writing a scientific article. J Sci Commun 2000;163:51-9.

Reference to a book:

[2] Strunk Jr W, White EB. The elements of style. 3rd ed. New York: Macmillan; 1979.

Reference to a chapter in an edited book:

[3] Mettam GR, Adams LB. How to prepare an electronic version of your article. In: Jones BS, Smith RZ, editors. Introduction to the electronic age, New York: EPublishing Inc; 1999, p. 281-304

Note shortened form for last page number. e.g., 51-9, and that for more than 6 Authors the first 6 should be listed followed by "et al." For further details you are referred to "Uniform Requirements for Manuscripts submitted to Biomedical Journals" (J Am Med Assoc 1997;277:927-934) (see also 마 http://www.nejm.org/general/text/requirements/1.htm).

Journal names should be abbreviated according to the Index Medicus journal abbreviations: Ł.http://www.nlm.nih.gov/tsd/serials/lji.html

Use of the Digital Object Identifier (DOI)

The digital object identifier (DOI) may be used to cite and link to electronic documents. The DOI consists of a unique alpha-numeric character string which is assigned to a document by the publisher upon the initial electronic publication. The assigned DOI never changes. Therefore, it is an ideal medium for citing a document, particularly 'Articles in press' because they have not yet received their full bibliographic information. The correct format for citing a DOI is shown as follows (example taken from a document in the journal Physics Letters B): doi:10.1016/j.physletb.2003.10.071

When you use the DOI to create URL hyperlinks to documents on the web, they are guaranteed never to change.

Preparation of illustrations 


\section{Preparation of electronic illustrations}

Submitting your artwork in an electronic format helps us to produce your work to the best possible standards, ensuring accuracy, clarity and a high level of detail.

\section{General points}

- Always supply high-quality printouts of your artwork, in case conversion of the electronic artwork is problematic.

- Make sure you use uniform lettering and sizing of your original artwork.

- Save text in illustrations as "graphics" or enclose the font.

- Only use the following fonts in your illustrations: Arial, Courier, Helvetica, Times, Symbol.

- Number the illustrations according to their sequence in the text.

- Use a logical naming convention for your artwork files, and supply a separate listing of the files and the software used.

- Provide all illustrations as separate files

- Provide captions to illustrations separately.

- Produce images near to the desired size of the printed version.

Files can be stored on diskette, ZIP-disk or CD (either MS-DOS or Macintosh). This journal offers electronic submission services and graphic files can be uploaded via

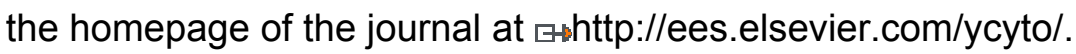

\section{A detailed guide about the preparation of electronic artwork is available on our website:}

๘-sttp://authors.elsevier.com/artwork

\section{Formats}

Regardless of the application used, when your electronic artwork is finalised, please "save as" or convert the images to one of the following formats (Note the resolution requirements for line drawings, halftones, and line/halftone combinations given below.):

EPS: Vector drawings. Embed the font or save the text as "graphics".

TIFF: Colour or greyscale photographs (halftones): always use a minimum of 300 dpi.

TIFF: Bitmapped line drawings: use a minimum of $1000 \mathrm{dpi}$.

TIFF: Combinations bitmapped line/half-tone (colour or greyscale): a minimum of $500 \mathrm{dpi}$ is required.

DOC, XLS or PPT: If your electronic artwork is created in any of these Microsoft Office applications please supply "as is".

\section{Please do not:}

- Supply embedded graphics in your wordprocessor (spreadsheet, presentation) document;

- Supply files that are optimised for screen use (like GIF, BMP, PICT, WPG); the resolution is too low;

- Supply files that are too low in resolution; 
- Submit graphics that are disproportionately large for the content.

\section{Captions}

Ensure that each illustration has a caption. Supply captions on a separate sheet, not attached to the figure. A caption should comprise a brief title (not on the figure itself) and a description of the illustration. Keep text in the illustrations themselves to a minimum but explain all symbols and abbreviations used.

Proofs

When your manuscript is received by the Publisher it is considered to be in its final form. Proofs are not to be regarded as "drafts".

One set of page proofs in PDF format will be sent by e-mail to the corresponding Author, to be checked for typesetting/editing. No changes in, or additions to, the accepted (and subsequently edited) manuscript will be allowed at this stage. Proofreading is solely your responsibility.

A form with queries from the copyeditor may accompany your proofs. Please answer all queries and make any corrections or additions required.

The Publisher reserves the right to proceed with publication if corrections are not communicated. Return corrections within 4 days of receipt of the proofs. Should there be no corrections, please confirm this.

Elsevier will do everything possible to get your article corrected and published as quickly and accurately as possible. In order to do this we need your help. When you receive the (PDF) proof of your article for correction, it is important to ensure that all of your corrections are sent back to us in one communication. Subsequent corrections will not be possible, so please ensure your first sending is complete. Note that this does not mean you have any less time to make your corrections, just that only one set of corrections can be accepted. 